\title{
$\alpha 2 \delta-1$ Signaling Drives Cell Death, Synaptogenesis, Circuit Reorganization, and Gabapentin-Mediated Neuroprotection in a Model of Insult-Induced Cortical Malformation
}

\author{
Lauren A. Lau, ${ }^{1,2}$ (1) Farzad Noubary, ${ }^{3,4}$ Dongqing Wang, ${ }^{5}$ and ${ }^{(1)}$ Chris G. Dulla ${ }^{1}$
}

DOI:http://dx.doi.org/10.1523/ENEURO.0316-17.2017

${ }^{1}$ Department of Neuroscience, Tufts University School of Medicine, Boston, MA 02111, ${ }^{2}$ Neuroscience Program, Tufts Sackler School of Biomedical Sciences, Boston, MA 02111, ${ }^{3}$ The Institute for Clinical Research and Health Policy Studies, Tufts Medical Center, Boston, MA 02111, ${ }^{4}$ Tufts Clinical and Translational Science Institute, Tufts University, Boston, MA 02111, and ${ }^{5}$ Department of Brain and Cognitive Sciences, Massachusetts Institute of Technology, Cambridge, MA 02139

Visual Abstract

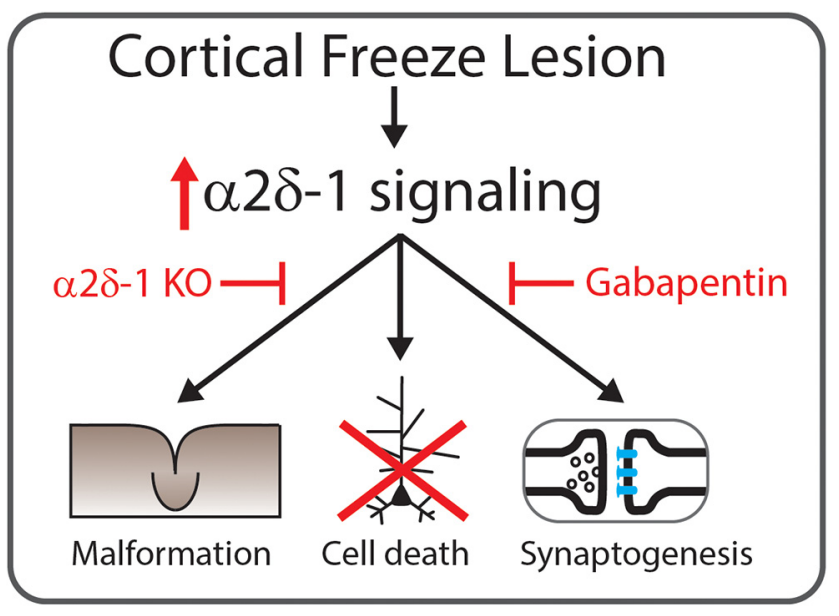

exuberant excitatory synaptogenesis and network hyperexcitability seen in DCMs. In that study, antagonizing $\mathrm{TSP} / \alpha 2 \delta^{-1}$ signaling using the drug gabapentin (GBP) reduced many FL-induced pathologies. Here, we used mice with a genetic deletion of $\alpha 2 \delta^{-1}$ to determine how $\alpha 2 \delta^{-1}$ contributes to cell death, elevated excitatory synapse number, and in vitro network function after FL and to examine the molecular specificity of GBP's effects. We

\section{Significance Statement}

$\alpha 2 \delta$-1 signaling drives apoptotic cell death, anatomic reorganization, excitatory synaptogenesis, astrocytosis, and network hyperexcitability in a model of insult-induced cortical malformation known as freeze lesion (FL). This is the first direct demonstration of $\alpha 2 \delta$-1's role in injury-induced cell death in the CNS, and suggests that $\alpha 2 \delta-1$ may be broadly involved in pathologic changes after neonatal brain insult. We also investigated the effects of gabapentin (GBP) in the absence of $\alpha 2 \delta-1$, a known site of drug action. Our studies show that genetic deletion of $\alpha 2 \delta$-1 eliminates GBP's neuroprotective effects, confirming a specific site of action. We also find that GBP can reduce FL-induced increases in excitatory synapse number in $\alpha 2 \delta$-1 knock-out (KO) mice, indicating GBP has $\alpha 2 \delta$-1-independent anti-synaptogenic effects. 
identified a critical role for $\alpha 2 \delta-1$ in FL-induced pathologies and in mediating the neuroprotective effects of GBP. Interestingly, genetic deletion of $\alpha 2 \delta$-1 did not eliminate GBP's effects on synaptogenesis, suggesting that GBP can have $\alpha 2 \delta$-1-independent effects. Taken together these studies suggests that inhibiting $\alpha 2 \delta$ - 1 signaling may have therapeutic promise to reduce cell death and network reorganization associated with insult-induced DCMs.

Key words: a2d-1; cell death; cortex; gabapentin; malformation; polymicrogyriax

\section{Introduction}

Developmental cortical malformations (DCMs) are characterized by an anatomically disorganized cortex and are associated with difficult to treat epilepsy (Crino, 2005; Takano et al., 2006). There are multiple DCM subsyndromes, including tuberous sclerosis, focal cortical dysplasia (FCD), and polymicrogyria. Both genetic and environmental causes of DCMs exist, with individual subsyndromes having their own etiology. These include mutations in genes responsible for neuronal proliferation, migration, and apoptosis (Barkovich et al., 2012), as well as neonatal insults including pre- and perinatal hypoxia, viral infection, and traumatic injury (Leventer et al., 2008; Blümcke et al., 2011). DCMs associated with neonatal insult (polymicrogyria and FCD Type IIId) may be more amenable to therapeutic intervention, as their precipitating insult is often rapidly clinically documented.

To better understand the molecular and cellular changes associated with early life insult-induced cortical network reorganization, we used the neonatal freeze-lesion $(F L)$ model. FL recapitulates key features of polymicrogyria and FCD Type Illd (Luhmann, 2016) including insultinduced etiology, cell death, astrocytosis, anatomic reorganization, and spontaneous seizures (Sun et al., 2016; Williams et al., 2016). Additionally, the FL model allows study of the changes that occur between insult and network dysfunction in a stereotyped model. Briefly, on the day of birth (postnatal day $0, \mathrm{P} 0$ ), a freezing probe is applied to the exposed skull, generating a hypoxic insult. This results in cell death and the formation of a microgyrus and a surrounding paramicrogyral zone (PMZ). The PMZ is hyperexcitable and generates epileptiform network activity beginning approximately two weeks after injury (Jacobs et al., 1996; Jacobs et al., 1999; Andresen

Received September 12, 2017; accepted October 13, 2017; First published October 23, 2017

The authors declare no competing financial interests.

Author contributions: L.A.L. and C.G.D. designed research; L.A.L. performed research; D.W. contributed unpublished reagents/analytic tools; L.A.L. and F.N. analyzed data; L.A.L. and C.G.D. wrote the paper.

This work was supported by the Department of Health and Human Services National Institutes of Health National Institute of Neurological Disorders and Stroke Grant R01-NS076885 (to C.G.D.), the Sackler School Deans Fellowship (L.A.L.), and the Tufts Center for Neuroscience Research Grant P30 NS047243.

Acknowledgments: We thank Moritz Armbruster, Danielle Croker, Charlene Rivera-Bonet, Pablo Gonzalez, and Kyle O'Donnell for their assistance and Guoping Feng for his generous gift of $\alpha 2 \delta-1 \mathrm{KO}$ mice.

Correspondence should be addressed to Chris G. Dulla, Tufts University, Department of Neuroscience, 136 Harrison Avenue, SC203, Boston, MA 02111, E-mail: chris.dulla@tufts.edu.

DOI:http://dx.doi.org/10.1523/ENEURO.0316-17.2017

Copyright $\odot 2017$ Lau et al.

This is an open-access article distributed under the terms of the Creative Commons Attribution 4.0 International license, which permits unrestricted use, distribution and reproduction in any medium provided that the original work is properly attributed. et al., 2014). Identifying the molecular, cellular, and network level changes that lead to brain dysfunction after neonatal cortical insult are paramount to developing novel therapeutic approaches.

Recently, we reported that thrombospondin (TSP)/ $\alpha 2 \delta-1$ signaling is increased in the cortex following FL (Andresen et al., 2014). TSP promotes excitatory synaptogenesis during development (Christopherson et al., 2005) by binding to $\alpha 2 \delta-1$ (Eroglu et al., 2009). $\alpha 2 \delta-1$ acts as an auxiliary subunit of voltage gated calcium channels, but its synaptogenic function appears to be independent of calcium channel association (Eroglu et al., 2009). Recent genetic studies have implicated $\alpha 2 \delta$-1 mutations in human polymicrogyria (Vergult et al., 2015). Of note, gabapentin (GBP) blocks the interaction of TSP and $\alpha 2 \delta$ - 1 and reduces $\alpha 2 \delta$-1-mediated excitatory synaptogenesis (Eroglu et al., 2009). There is reason to suspect that brain injury reactivates $\mathrm{TSP} / \alpha 2 \delta-1$, leading to hyperexcitation. In vivo GBP treatment attenuates injury-induced increases in synaptogenesis (Li et al., 2012; Li et al., 2014; Takahashi et al., 2017) following adult brain injury, and reduces excitatory synaptic transmission and cortical hyperexcitability following FL (Andresen et al., 2014). Interestingly, GBP is also neuroprotective in models of spinal cord injury (Emmez et al., 2010; Kale et al., 2011), cortical trauma (Li et al., 2012) and stroke (Traa et al., 2008; Kim et al., 2010). It is unknown, however, whether $\alpha 2 \delta-1$ activity contributes to cell death or if GBP's neuroprotective effects are mediated by its actions on $\alpha 2 \delta-1$.

In this study, we examined the role of $\alpha 2 \delta-1$ in FLassociated pathologies (cell death, cortical reorganization, astrocytosis, excessive synaptic excitation, and network hyperexcitability) and GBP-mediated neuroprotection. We used both pharmacological blockade and genetic deletion of $\alpha 2 \delta-1$ and found that both reduced apoptotic cell death following FL. Attenuating $\alpha 2 \delta$-1 signaling pharmacologically or genetically helped restore normal cortical structure following FL, reduced astrocyte reactivity, and attenuated FL-induced increases in excitatory synapse number and glutamatergic synaptic transmission. The vast majority of GBP's effects were absent in mice lacking $\alpha 2 \delta-1$, confirming that GBP acts largely through $\alpha 2 \delta-1$. Our studies of synapse number, however, suggest GBP may also have $\alpha 2 \delta$-1-independent effects. Additionally, cortical hyperexcitability is only partially rescued in $\mathrm{FL}$ mice deficient in $\alpha 2 \delta-1$, consistent with other pathways contributing to dysfunction following neonatal cortical insult. To enhance the rigor of this study we also employed a linear mixed model statistical approach and found that GBP and $\alpha 2 \delta-1$ have robust effects on FL pathology. Overall, our study suggests that $\alpha 2 \delta-1$ may be involved in driving multiple pathologies associated with insult- 
induced DCMs, as well as in mediating the neuroprotective effects of GBP.

\section{Materials and Methods}

\section{Animals}

All guidelines of Tufts University's Institutional Animal Care and Use Committee were followed. $\alpha 2 \delta$-1 knock-out (KO; $\alpha 2 \delta-1^{-/-}$) animals were generated by crossing heterozygous $\left(\alpha 2 \delta-1 \pm\right.$ ) pairs. Wild-type (WT; $\left.\alpha 2 \delta-1^{+/+}\right)$littermates were used as controls. $\alpha 2 \delta 1^{-1-}$ mice were a generous gift of Guoping Feng (Massachusetts Institute of Technology). Mice were maintained on a C57BL6/J background and back crossed for $>20$ generations. All experiments use mice from multiple litters to reduce litter to litter variability.

\section{FL}

Experimental microgyri in primary somatosensory cortex (right hemisphere) were induced in PO WT or $\alpha 2 \delta-1 \mathrm{KO}$ mouse pups by freeze lesioning as described previously (Andresen et al., 2014). Briefly, animals were anesthetized by hypothermia, an incision into the scalp was made, and a copper probe cooled to $-50^{\circ} \mathrm{C}$ to $-60^{\circ} \mathrm{C}$ was placed onto the exposed skull for 5 secs. Sham operated littermates were generated by leaving the probe at room temperature. After freeze-lesioning, the incision was closed using surgical glue, and pups were warmed and returned to the dam. All FL surgeries were performed by the same experimenter to reduce variability in the procedure, who was blinded to the genotype/treatment group.

\section{Drug treatments}

For drug treatment experiments, mice were treated with once daily intraperitoneal injections of either GBP (200 $\mathrm{mg} / \mathrm{kg}$ ) or vehicle (sterile injection saline) from P1 to P7.

\section{Western blotting}

Expression of $\alpha 2 \delta-1$ was analyzed via western blot. Cortex from adult $\alpha 2 \delta-1 \mathrm{KO}$ and WT littermates was dissected and homogenized using lysis buffer ( $0.2 \%$ SDS, $50 \mathrm{mM} \mathrm{NaF}$, and $1 \mathrm{mM}$ EDTA). Buffer (10 mM Tris, pH 8, $150 \mathrm{mM} \mathrm{NaCl}, 5 \mathrm{mM}$ EDTA, $1 \%$ Triton X-100, $10 \mathrm{mM} \mathrm{NaF}$, $2 \mathrm{mM} \mathrm{Na}_{3} \mathrm{VO}_{4}$, and $10 \mathrm{mM} \mathrm{Na} \mathrm{P}_{2} \mathrm{O}_{7}$ ) with $100 \times$ Halt protease inhibitor cocktail was added and samples were spun down for $15 \mathrm{~min}$ at $4^{\circ} \mathrm{C}$. Loading buffer $(10 \mu \mathrm{l}$ 2-mercaptoethanol and $190 \mu \mathrm{l}$ Laemmli buffer) was added to samples $1: 1$ and samples were heated to $70^{\circ} \mathrm{C}$ for $10 \mathrm{~min}$. A total of $25 \mu \mathrm{g}$ of protein was loaded onto a $10 \%$ SDS-PAGE gel and analyzed via electrophoresis. Protein was detected using antibodies for $\alpha 2 \delta-1$ (1:500, Abcam RRID:AB_303365), and anti- $\beta$-actin (1:1000, Abcam) was used to confirm equal loading. Protein bands were visualized using enhanced chemiluminescence and imaged with a LAS-3000 imaging system.

\section{Behavioral tests}

Ten-week-old male mice were used for behavioral testing. Behavioral assays were performed in the Tufts Center for Neuroscience Research Animal Behavior Facility. Animals were tested on a battery of tests, starting with the least stressful test (open field) and moving to more stress- ful tests (spontaneous alteration and rotarod) on subsequent days.

\section{Open field test}

Mice were individually placed into the center of a $40 \times$ $40 \mathrm{~cm}$ open field apparatus with $16 \times 16$ equally spaced photocells (Hamilton-Kinder). The total distance traveled, and the amount of time spent in the center of the open field, as well as the total number of beam breaks, were measured during the 20-min test using MotorMonitor software (Hamilton-Kinder).

\section{Spontaneous alteration}

Mice were placed in a three arm T-maze. After being placed in the starting arm, the barrier was removed to allow the rodent free choice to enter either the left or right arm. After entering an arm, a barrier was placed to keep the animals in that arm for $30 \mathrm{~s}$. The mouse was returned to the home cage for $1 \mathrm{~min}$ between trails and a total of 10 trials were performed. Generally, rodents will engage in exploratory behavior in the maze and alternate between the arms. The percentage of trials in which the animal spontaneously alternated arms was reported.

\section{Rotarod}

Motor coordination and balance was measured in the mice using an acceleration paradigm on a five position rotarod (ENV 577M, Med Associates). Mice were trained at a constant, slow speed of $14 \mathrm{rpm}$ until they could successfully stay on the beam for 5 min. Testing was conducted using a fast acceleration paradigm (4-40 rpm over $5 \mathrm{~min}$ ). Mice were tested over the course of three trials ( 30 min apart) and latency to fall and the RPM at which mice fall was reported.

\section{Electroencephalogram (EEG) recording}

Naïve, 10-week-old WT and $\alpha 2 \delta$-1 KO littermates were implanted for EEG recording based on a Tufts Institutional Animal Care and Use Committee approved protocol. Briefly, animals were anesthetized $(100 \mathrm{mg} / \mathrm{kg}$ ketamine and $10 \mathrm{mg} / \mathrm{kg}$ xylazine). An incision was made on the scalp, the surface of the skull was dried, and four burr holes were drilled with care to avoid puncturing the dura. Four 0.1" stainless steel screws (Pinnacle Technologies) were gently screwed into the drilled holes. A common reference electrode was placed anterior to the left side of the intraparietal bone, and two EEG electrodes were placed in the left front bone (for front/motor cortex) and in the right parietal bone (for somatosensory cortex). A separate ground electrode was also placed anterior to the right side of the intraparietal bone. The screws were then attached to a headmount (Pinnacle Technology), which was fixed using dental cement. Following surgery, the animals were given $7 \mathrm{~d}$ to recover. Chronic 24-h EEG recordings were acquired using a $100 \times$ gain preamplifier high-pass filtered at $1.0 \mathrm{~Hz}$ (Pinnacle Technology) with video monitoring for two weeks. LabChart Pro software (ADInstruments, RRID:SCR_001620) was used for data acquisition and analysis. 


\section{Preparation of acute brain slices}

Cortical brain slices containing sensorimotor cortex $(400 \mu \mathrm{M})$ were prepared from mice of either sex. Briefly, mice were anesthetized with isoflurane, decapitated, and the brains were rapidly removed and placed in chilled $\left(4^{\circ} \mathrm{C}\right)$ low-Ca, low-Na slicing solution consisting of 234 $\mathrm{mM}$ sucrose, $11 \mathrm{mM}$ glucose, $24 \mathrm{mM} \mathrm{NaHCO}{ }_{2}, 2.5 \mathrm{mM}$ $\mathrm{KCl}, 1.25 \mathrm{mM} \mathrm{NaH}_{2} \mathrm{PO}_{4}, 10 \mathrm{mM} \mathrm{MgSO}$, and $0.5 \mathrm{mM}$ $\mathrm{CaCl}_{2}$, equilibrated with a mixture of $95 \% \mathrm{O}_{2} / 5 \% \mathrm{CO}_{2}$. The brain was glued to the slicing stage of a Vibratome 3000 sectioning system and slices were cut in a coronal orientation. The slices were then incubated in $32^{\circ} \mathrm{C}$ oxygenated aCSF $(126 \mathrm{mM} \mathrm{NaCl}, 2.5 \mathrm{mM} \mathrm{KCl}, 1.25 \mathrm{mM}$ $\mathrm{NaH}_{2} \mathrm{PO}_{4}, 1 \mathrm{mM} \mathrm{MgSO}$, $2 \mathrm{mM} \mathrm{CaCl}, 10 \mathrm{mM}$ glucose, and $26 \mathrm{mM} \mathrm{NaHCO}_{2}$ ) for $1 \mathrm{~h}$, and then allowed to cool to room temperature and subsequently used for recording.

\section{Field recordings}

Slices were placed in an interface chamber maintained at $34^{\circ} \mathrm{C}$, superfused with oxygenated aCSF at $2 \mathrm{ml} / \mathrm{min}$ and cortical projections were stimulated with a tungsten concentric bipolar electrode at the Layer VI, white matter boundary. Electrical stimulation consisted of $10-50 \mu \mathrm{A}$, $100-\mu$ s pulses at $30-s$ intervals delivered by a stimulus isolator (World Precision Instruments). Glass micropipettes (resistance $\cong 1 \mathrm{M} \Omega$ ) were filled with aCSF and placed in Layer $V \sim 200 \mu \mathrm{m}$ from the site of injury in the PMZ of FL animals (or comparable area of cortex in sham-injured animals) directly above the stimulation electrode. Electrophysiological data were recorded with an Axon Multiclamp 700A amplifier and Digidata 1322A digitizer (sampling rate $=20 \mathrm{kHz}$ ) with Lab Chart software (AD Instruments, RRID:SCR_001620). Threshold stimulation intensity was identified as the minimum amount of current required to elicit a detectable cortical field potential response $(\geq 0.05 \mathrm{mV})$.

\section{Whole-cell patch-clamp recordings}

Slices were placed in the recording chamber of an Olympus Bx51 microscope with continual superfusion of oxygenated aCSF maintained at $32^{\circ} \mathrm{C}(2 \mathrm{ml} / \mathrm{min})$. Layer $\mathrm{V}$ pyramidal neurons were visually identified with infrared differential interference contrast microscopy and wholecell patch-clamp recordings were made with a borosilicate glass electrode ( $3-5 \mathrm{M} \Omega$ ) filled with $140 \mathrm{mM}$ CsMs, $10 \mathrm{mM}$ HEPES, $5 \mathrm{mM} \mathrm{NaCl}, 0.2 \mathrm{mM}$ EGTA, $5 \mathrm{mM}$ Qx314, $1.8 \mathrm{mM}$ MgATP, and $0.3 \mathrm{mM}$ NaGTP; $\mathrm{pH}$ 7.25. The recording electrode was placed $\sim 200 \mu \mathrm{m}$ from the site of injury in the PMZ of FL animals, or comparable cortical area in sham-injured animals. Data were collected using an axon Multiclamp 700B amplifier, Digidata 1440A digitizer and pClamp software. Miniature EPSCs (mEPSCs) were recorded at a holding potential of $-70 \mathrm{mV}$ in the presence of $1 \mu \mathrm{M}$ TTX. Only recordings with an access resistance that varied $<20 \%$ were accepted for analysis.

\section{Electrophysiological data analysis}

Field recordings were analyzed using Lab Chart (AD Instruments, RRID:SCR_001620), pClamp (Molecular Devices, RRID:SCR_011323) and MATLAB software (RRID: SCR_001622). Traces were recorded at threshold stimu- lation, the minimum stimulation required to elicit a detectable response. Each sweep was analyzed for epileptiform activity to calculate the percentage of epileptiform activity per slice. The area under the curve was used to determine the integrated network activity and was calculated by integrating the extracellular field potential during the first $1000 \mathrm{~ms}$ following initial stimulation. mEPSC recordings were analyzed using Clampfit (Molecular Devices, RRID: SCR_011323) and Mini Analysis (Synaptosoft, RRID: SCR_002184). Recordings of 60-120 s were analyzed for average amplitude and interevent frequency.

\section{Immunohistochemistry}

Fixed mouse brains were prepared by transcardial perfusion with PBS followed by overnight fixation with $4 \%$ paraformaldehyde. Fixed brains were sectioned at $40 \mu \mathrm{m}$ using a Thermo Fisher Microm HM 525 cryostat. Brain sections were blocked using blocking buffer ( $5 \%$ normal goat serum, $1 \%$ bovine serum albumin, in PBS) for $1 \mathrm{~h}$ at room temperature. Glial fibrillary acid protein (GFAP) (1: 500, Abcam, RRID:AB_305808), NeuN (1:1000, Millipore, RRID:AB_2298772), CUX1 (1:100, Santa Cruz, RRID: AB_2261231), CTIP2 (1:500, Abcam, RRID:AB_2064130), and activated caspase-3 (1:500, Abcam, RRID:AB_443014) antibodies were diluted in PBS with $2 \%$ Triton X-100 and $5 \%$ blocking buffer. Cortical sections were incubated with diluted primary antibodies overnight at $4^{\circ} \mathrm{C}$. Appropriate secondary antibodies (The Jackson Laboratory) were diluted in PBS with 5\% blocking buffer and added to cortical sections for $2 \mathrm{~h}$ at room temperature. Slices were mounted using Vectashield (Vector Labs) and imaged with a Keyence BZ-X700 fluorescence microscope or Nikon A1R confocal microscope. All staining was analyzed with ImageJ (RRID:SCR_003070).

\section{Synapse counting}

Tissue preparation, staining and analysis was adapted from the protocol from Ippolito and Eroglu (Ippolito and Eroglu, 2010). Brains were fixed as above and sectioned at $14 \mu \mathrm{m}$. Brain sections were blocked using $20 \%$ normal goat serum in PBS for $1 \mathrm{~h}$ at room temperature. Vglut1 (1:2500, Millipore, RRID:AB_2301751), PSD95 (1:500, Invitrogen, RRID:AB_2533914), and GFAP (1:1000, Abcam, RRID:AB_296804) were diluted in PBS with 0.3\% Triton $\mathrm{X}-100$ and $10 \%$ normal goat serum. Cortical sections were incubated with diluted primary antibodies for $42 \mathrm{~h}$ at $4^{\circ} \mathrm{C}$. Appropriate secondary antibodies (The Jackson Laboratory) were diluted in PBS with 0.3\% Triton X-100 and $10 \%$ normal goat serum and added to cortical sections for $2 \mathrm{~h}$ at room temperature. Slices were mounted using fluoromount-G (Southern Biotech) and imaged with a Nikon A1R confocal microscope. Images were collected with a $100 \times$ oil immersion objective and maximum intensity projections (MIPs), of three serial optical sections at $0.175-\mu \mathrm{m}$ steps, were generated. Five MIPs were generated and analyzed per section. These were averaged to give one value per brain section. Synapses were quantified in ImageJ (RRID:SCR_003070) using the Puncta Analyzer plug in. 


\section{Terminal deoxynucleotidyl transferase dUTP nick end labeling (TUNEL) assay}

Brains were prepared by transcardial perfusion with PBS followed by overnight fixation with $4 \%$ paraformaldehyde. Fixed brains were sectioned at $40 \mu \mathrm{m}$ using a Thermo Fisher Microm HM 525 cryostat. TUNEL was detected using an ApopTag peroxidase in situ apoptosis detection kit (Millipore). Briefly, endogenous peroxidase activity was blocked by incubation of the sections with $3 \% \mathrm{H}_{2} \mathrm{O}_{2}$ for 5 min. TdT enzyme provided by the kit was used to label dUTP nick ends with DAB as the substrate. Nuclei were counterstained with methyl green and slices were mounted using Permount (Fisher Scientific). Tissue sections were evaluated by conventional bright-field microscopy and analyzed in ImageJ. The color deconvolution plug-in was used to isolate the DAB component of the staining. TUNEL-positive cells were quantified using the puncta analyzer in ImageJ. A uniform threshold and puncta size was applied across all images. The density of TUNEL-positive cells was quantified based on the number of TUNEL-positive cells in the region of interest which spanned from pial surface to the cortex white matter border and $\sim 500 \mu \mathrm{m}$ on either side of the site of lesion.

\section{Experimental design and statistical analysis}

For all studies, control experiments were performed including sham injury and age-matched vehicle treatment. Additionally, WT littermates were used as controls in experiments testing the effect of genetic deletion of $\alpha 2 \delta-1$. Multiple litters were used for each experiment to control for litter to litter differences. GBP versus vehicle and sham versus FL was randomized by litter, ensuring a mix of treatments and genotypes throughout all studies. The distribution of genotypes followed a Mendelian distribution. The sex of the mice was $\sim 50 \%$ male and $50 \%$ female. Animals were randomly assigned to one of four treatment groups. The experimenter was blind to genotype at the time of FL and drug treatment. Data analysis was not blinded, but many assays use automated, quantitative analysis which helps to reduce potential bias in many experiments. The majority of experiments in this study had three between-subject factors being tested: sham versus FL, WT versus $\alpha 2 \delta-1 \mathrm{KO}$, and vehicle versus GBP treatment. Each experimental group for electrophysiology and immunohistochemistry experiments consisted of three to four animals, with eight different experimental groups (WT sham + vehicle, KO sham + vehicle, WT sham + GBP, KO sham + GBP, WT FL + vehicle, KO FL + vehicle, WT FL +GBP, and KO WT +GBP). Exact animal number and slice/cell number is noted in the results. Sample size has been calculated to ensure power $>0.8$ for $\alpha=0.05$. Power was calculated using $\mathrm{G} *$ Power Software. All experiments used animals of the same age between groups.

For comparison between two experimental groups, a Student's $t$ test was used. To control for multiple comparisons (with three or more experimental groups), a oneway ANOVA was used. For comparison of cumulative probabilities, a Kolmogorov-Smirnov test (KS test) was used. For all experiments, we compared WT FL to WT
Sham, WT FL to WT FL + GBP, WT FL to KO FL, and KO $\mathrm{FL}$ to $\mathrm{KO} F \mathrm{FL}$ GBP. To control for multiple comparisons, a Holm-Bonferroni correction was used. All data are presented as box-whisker plots \pm SEM, with average values indicated by $X$ on the plots. Exact $P$ values are indicated in the results, unless they were $<0.001$; values of $p<0.05$ for $\alpha=0.05$ or less were considered statistically significant. OriginLab and MATLAB software was used to perform the statistical analyses.

In addition, to perform more rigorous statistical analysis linear mixed-effects models were fitted with random intercepts to account for the correlation between repeated measurements on the same mouse. To standardize the modeling procedure and facilitate comparison across the experiments, fixed effects always included main effects for FL, drug treatment, and genetic $\mathrm{KO}$ of $\alpha 2 \delta-1$, as well as interaction terms between FL and drug treatment, FL and genetic $\mathrm{KO}$ of $\alpha 2 \delta-1$, and drug treatment and genetic KO of $\alpha 2 \delta-1$. In other words, sham, vehicle, and WT served as reference categories. $t$ values $>1.96$ and $<$ -1.96 we considered to be statistically significant.

\section{Drugs and reagents}

All salts and glucose for buffers were obtained from Sigma-Aldrich. GBP was obtained from Abcam.

\section{Results}

\section{Pharmacological attenuation of $\alpha 2 \delta$-1 signaling decreases cell death following FL}

GBP treatment has been shown to reduce cell death in models of posttraumatic epilepsy (Li et al., 2012) and stroke (Traa et al., 2008), suggesting that $\alpha 2 \delta-1$ signaling may contribute to insult-induced cortical cell death. Here, we tested whether attenuating $\alpha 2 \delta-1$ signaling via in vivo GBP treatment was neuroprotective in the FL model. As described in previous studies, FL was performed in C57BL/6J mice on the day of birth (P0). To identify dead and dying cells in the neonatal cortex, we used TUNEL labeling and activated caspase- 3 immunolabeling (Watanabe et al., 2002). We found that FL induced significant cell death in the cortex at P7 (Fig. 1; caspase-3 immunoreactivity: sham, $4.1 \pm 1.0$ cells per $0.1 \mathrm{~mm}^{2}, n=11$ sections from four animals; FL, $61.5 \pm 4.4$ cells per 0.1 $\mathrm{mm}^{2}, n=10$ sections from three animals; Mann-Whitney, $U_{(19)}=0, p<0.001$; Holm-Bonferroni correction for multiple comparisons, $\alpha=0.001$; TUNEL: sham, $0.5 \pm 0.2$ cells per $0.1 \mathrm{~mm}^{2}, n=7$ sections from three animals; FL, $59.1 \pm 16.6$ cells per $0.1 \mathrm{~mm}^{2}, n=8$ sections from four animals; Mann-Whitney, $U_{(13)}=0, p<0.001$; HolmBonferroni correction for multiple comparisons, $\alpha=$ 0.001). The majority of cell death was seen at the site of FL and in the surrounding cortical tissue. Other developmental time points were examined and the peak expression of cell death markers was seen at approximately P5-P7 (data not shown). Therefore, the effects of $\alpha 2 \delta$-1 signaling on cell death were quantified at P7.

To determine the role of $\alpha 2 \delta$ - 1 signaling in FL-induced cell death, we first treated animals with GBP after FL. Sham and FL animals were treated with $200 \mathrm{mg} / \mathrm{kg}$ GBP or vehicle (intraperitoneal injection) once daily from P1 to 
A

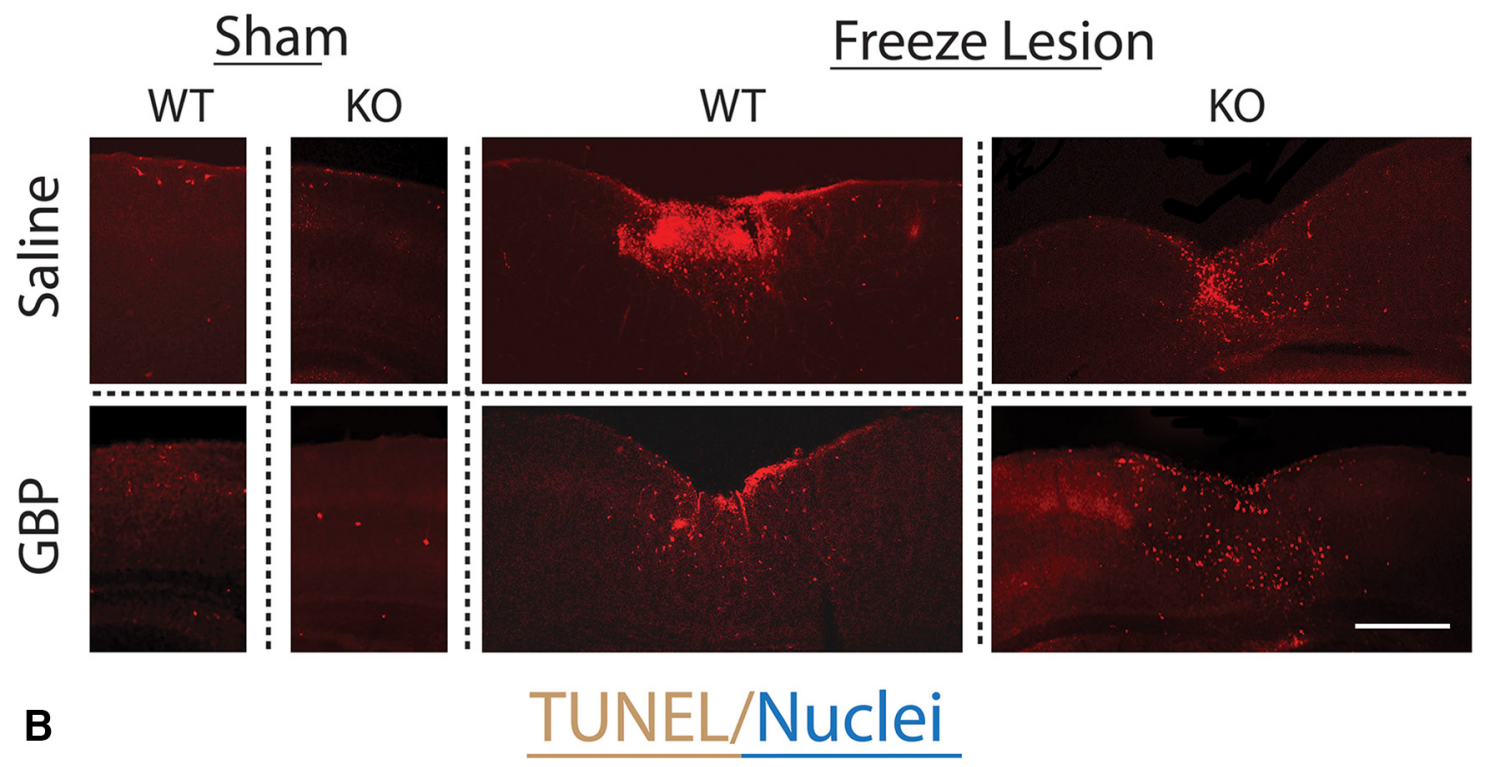

Sham
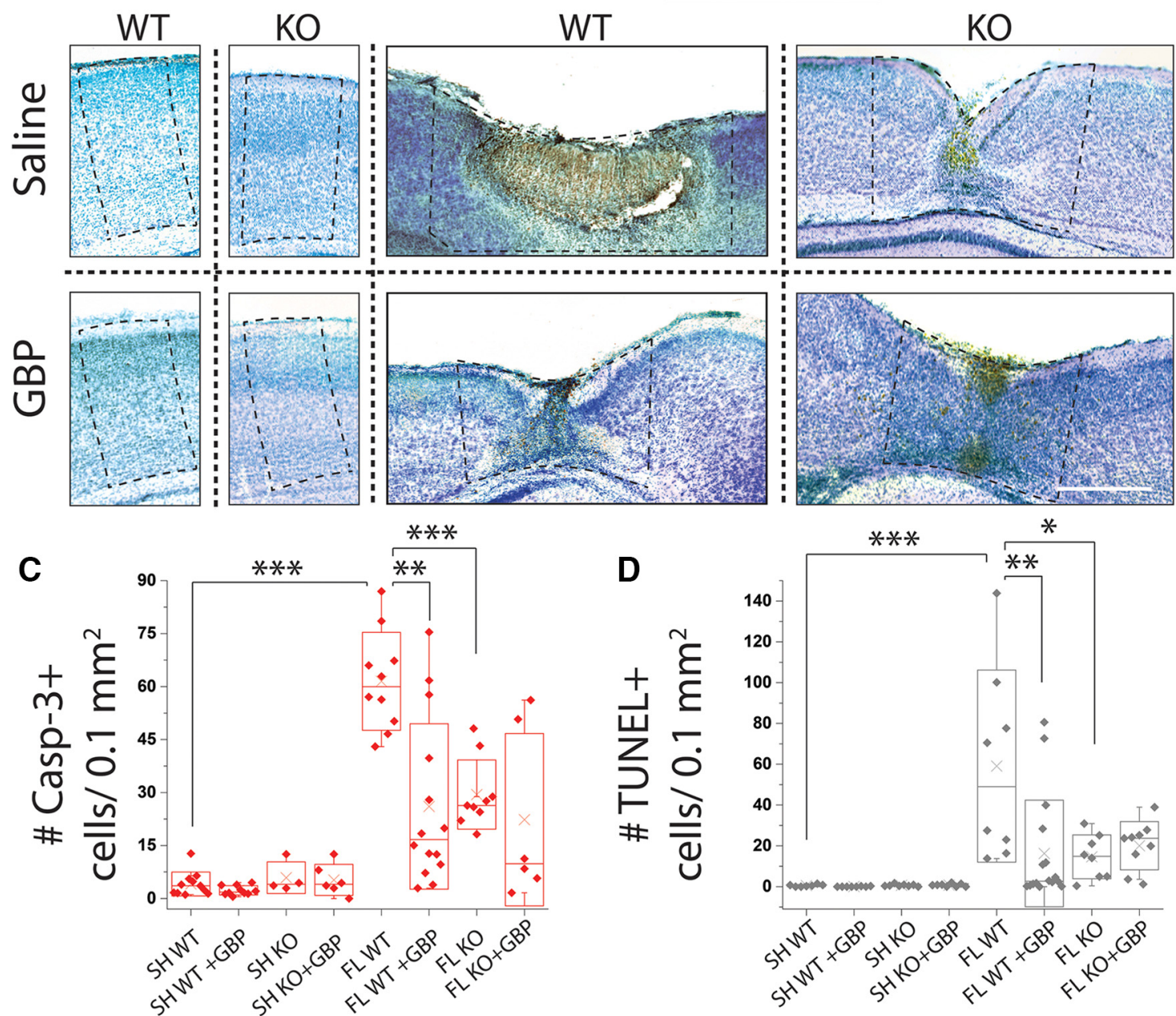

Figure 1. GBP treatment or $\alpha 2 \delta$-1 deletion decreases cell death following FL. $\boldsymbol{A}$, Representative images of cleaved caspase-3 (casp-3) staining in P7 WT and $\alpha 2 \delta_{-1}^{-1-}$ sham \pm GBP and WT and $\alpha 2 \delta^{-1} 1^{-/-} \mathrm{FL} \pm$ GBP. Scale bar $=500 \mu \mathrm{m}$. B, Representative bright-field 
continued

images of TUNEL assay (TUNEL + cells stained brown by DAB, nuclei counterstained by methyl green) in P7 WT and $\alpha 2 \delta-1{ }^{-1-}(\mathrm{KO})$ sham \pm GBP and WT and $\alpha 2 \delta-1^{-1-} \mathrm{FL} \pm \mathrm{GBP}$. Scale bar $=500 \mu \mathrm{m}$. Approximate ROI for analysis shown in dashed box. $\boldsymbol{C}$, Box-whisker plot of casp-3+ cells per $0.1 \mathrm{~mm}^{2}, * * \alpha=0.01$ and $* * * \alpha=0.001$ (Holm-Bonferroni multiple-comparison correction). $\boldsymbol{D}$, Box-whisker plot of TUNEL+ cells per section, $* \alpha=0.05$, $* * \alpha=0.01$, and $* * * \alpha=0.001$ (Holm-Bonferroni multiple-comparison correction).

P7. We found that GBP treatment significantly reduced cell death following FL, as measured using both assays (Fig. 1; caspase-3 immunoreactivity: $26.1 \pm 6.2$ cells per $0.1 \mathrm{~mm}^{2}, n=14$ sections from four animals; MannWhitney, $U_{(22)}=122, p=0.003$; Holm-Bonferroni correction for multiple comparisons, $\alpha=0.01$; TUNEL: $19.9 \pm$ 7.7 cells per $0.1 \mathrm{~mm}^{2}, n=13$ sections from four animals; $U_{(19)}=219, p<0.001$; Holm-Bonferroni correction for multiple comparisons, $\alpha=0.001)$. Very few cells expressed either marker of cell death in GBP-treated sham animals (caspase- 3 immunoreactivity: $2.3 \pm 0.4$ cells per $0.1 \mathrm{~mm}^{2}, n=10$ sections from three animals; TUNEL: $0.1 \pm 0.04$ cells per $0.1 \mathrm{~mm}^{2}, n=8$ sections from three animals).

\section{Genetic deletion of $\alpha \mathbf{2} \delta$-1 attenuates FL-induced cell death}

Next, we examined whether genetic deletion of $\alpha 2 \delta-1$ recapitulated GBP's neuroprotective effects after FL. Mice lacking the $\alpha 2 \delta-1$ gene CACNA2D1 ( $\alpha 2 \delta$-1 KOs) were generated and the absence of the $\alpha 2 \delta$-1 protein was confirmed by Western blot analysis of total cortical homogenate (data not shown). These mice showed no obvious phenotype and developed normally with regard to size and weight. $\alpha 2 \delta-1 \mathrm{KO}$ mice were recently reported to have a higher risk of developing diabetes due to changes in pancreatic $\beta$-cell function (Mastrolia et al., 2017). $\alpha 2 \delta$-1 KOs showed no change in open field activity or time spent in the center of the open field and performed normally on the rotarod and alternating T-maze test (data not shown). No behavioral or electrographic seizures were detected in $\alpha 2 \delta-1$ KOs subjected to two weeks of $24 / 7$ video/EEG monitoring (data not shown).

After characterizing the $\alpha 2 \delta-1 \mathrm{KO}$ mice, we performed FL experiments. We found that mice lacking $\alpha 2 \delta-1(\alpha 2 \delta-1$ $\mathrm{KO}$ ) had reduced cell death at P7 following FL (Fig. 1; caspase-3 immunoreactivity: $38.8 \pm 9.7$ cells per 0.1 $\mathrm{mm}^{2}, n=10$ sections from three animals; $t$ test, $t_{(17)}=$ 5.75, $p<0.001$ as compared to WT FL; Holm-Bonferroni correction for multiple comparisons, $\alpha=0.001$; TUNEL: $14.6 \pm 3.8$ cells per $0.1 \mathrm{~mm}^{2}, n=7$ sections from three animals; $t$ test, $t_{(14)}=2.79, p=0.01$; Holm-Bonferroni correction for multiple comparisons, $\alpha=0.05$ ), consistent with $\alpha 2 \delta-1$ signaling contributing to FL-induced cell death. Previously, it has been unknown whether GBP's effects on cell death act via $\alpha 2 \delta$-1 signaling or via another pathway. To test this, we treated $\alpha 2 \delta-1 \mathrm{KO}$ animals with GBP after FL. GBP treatment did not further reduce cell death in $\alpha 2 \delta-1 \mathrm{KO}$ animals (Fig. 1; caspase- 3 immunoreactivity: $22.3 \pm 9.9$ cells per $0.1 \mathrm{~mm}^{2}, n=6$ sections from three animals; TUNEL: $19.7 \pm 3.4$ cells per $0.1 \mathrm{~mm}^{2}, n=$ 8 sections from three animals). This indicates that GBP likely acts via $\alpha 2 \delta-1$ to reduce cell death, as GBP has no additional neuroprotective effects in $\alpha 2 \delta-1 \mathrm{KO}$ mice. Neither GBP treatment, nor genetic deletion of $\alpha 2 \delta$-1, completely eliminated cell death consistent with other cell death pathways likely contributing to neuronal loss following FL.

\section{Attenuating $\alpha 2 \delta$-1 signaling reduces FL-induced cortical malformation}

Because genetic and pharmacological inhibition of $\alpha 2 \delta-1$ signaling reduced cell death, we hypothesized that similar manipulations would decrease FL-induced cortical reorganization. To test this hypothesis, we examined anatomic changes induced by FL in GBP-treated and $\alpha 2 \delta-1$ $\mathrm{KO}$ animals. Because FL creates a 3-dimensional cortical malformation, we prepared serial cortical brain sections from P28 FL animals that encompassed the entire FL (Fig. 2D). We identified areas of malformation, characterized by large-scale cortical disorganization, by examining NeuN (marker of neurons) immunolabeled sections. The area of malformed, or missing, cortex was quantified throughout the reconstructed cortex. When FL resulted in loss of cortical tissue, this loss was quantified by drawing a line continuous with the adjacent pial surface and calculating the area of predicted tissue loss. The area of missing cortex was added to the area of malformed cortex to calculate lesion area per slice. The area was calculated in serial sections through the volume of the lesion and used to estimate the total lesion volume. Consistent with our cell death data, the volume of the lesion was decreased in FL animals treated with GBP from P1 to P7 (Fig. 2A,B; FL: $1.65 \pm 0.13 \mathrm{~mm}^{3}, n=$ three animals vs FL + GBP: $1.25 \pm$ $0.03, n=$ three animals; one-way ANOVA, $F_{(3)}=8.01, p=$ 0.003 ; post hoc Bonferroni test, $\alpha=0.05$ ). $\alpha 2 \delta-1 \mathrm{KO}$ mice also showed reduced lesion size compared to WT FL (Fig. $2 A, B ; 1.08 \pm 0.13 \mathrm{~mm}^{3}, n=4$ and $1.16 \pm 0.06 \mathrm{~mm}^{3}, n=$ 4 for vehicle and GBP-treated animals, respectively; post hoc Bonferroni test, $\alpha=0.05)$. These results demonstrate that reducing $\alpha 2 \delta$-1 signaling with either GBP treatment or $\alpha 2 \delta-1 \mathrm{KO}$ reduces the areas of cortical malformation following FL. Similar to cell death data, treating $\alpha 2 \delta-1 \mathrm{KO}$ animals with GBP did not result in additional reductions in cortical malformation (Fig. $2 A, B ; 1.16 \pm 0.06 \mathrm{~mm}^{3}, n=4$ ). This again suggests that GBP's neuroprotective effects are mediated by $\alpha 2 \delta-1$.

\section{Attenuating $\alpha 2 \delta$-1 signaling decreases GFAP immunoreactivity following $\mathrm{FL}$}

In parallel to measuring lesion volume, we also examined immunoreactivity for GFAP, a protein that is strongly upregulated by reactive astrocytes in the cerebral cortex. Our previous work, and the work of others, shows that FL causes significant reactive astrocytosis (Bordey et al., 2001; Dulla et al., 2013; Armbruster et al., 2014; Campbell 
A

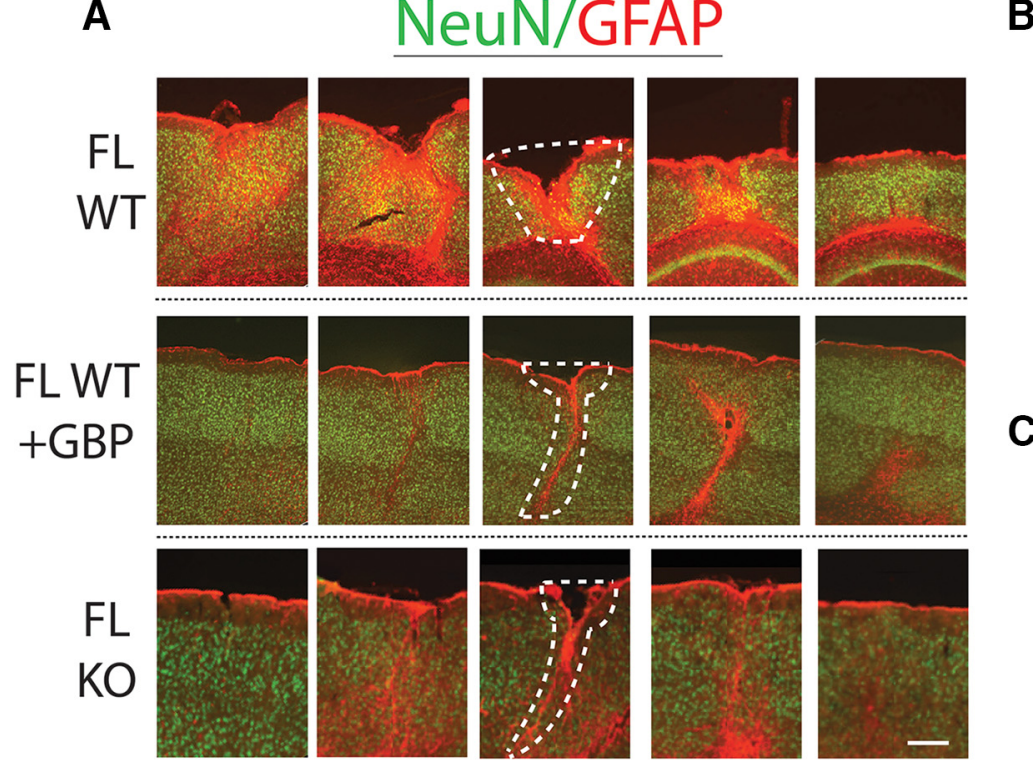

B

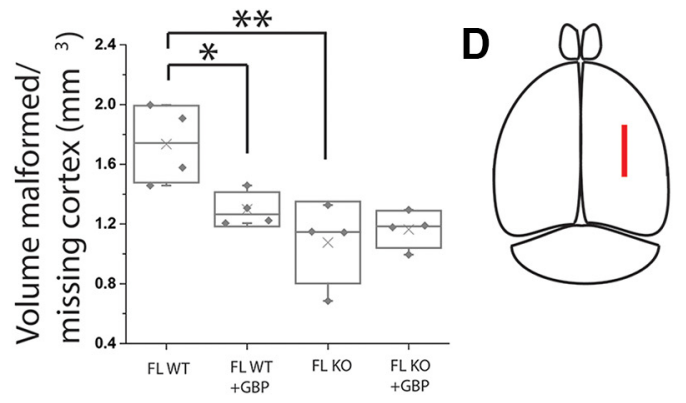

Figure 2. GBP treatment or $\alpha 2 \delta-1 \mathrm{KO}$ decreases malformation volume and astrocyte reactivity after FL. $\boldsymbol{A}$, GFAP (red) and NeuN (green) staining in P28 WT FL, WT GBP-treated FL, and $\alpha 2 \delta^{-1} 1^{-/-}(\mathrm{KO})$ FL cortex. Serial sections taken at 480- $\mu \mathrm{m}$ intervals, spanning the total length of the MZ. Scale bar $=100 \mu \mathrm{m}$. Dotted white line showing area of both missing and malformed cortical tissue. $\boldsymbol{B}$, Box-whisker plot of volume of missing or malformed cortex $\left(\mathrm{mm}^{3}\right)$, estimated from area calculated in serial sections, $* p<0.05$ and $* * p<0.01$. C , Box-whisker plot of percentage of GFAP-positive pixels in $\sim 600 \mu \mathrm{m}^{2} \mathrm{ROI}$ from white matter to the pial surface, centered around the MZ, $* p<0.05$ and $* * p<0.01$. D, Illustration depicting location of FL injury.

et al., 2014; Hanson et al., 2016). To quantify GFAP labeling in the cortex, we examined immunolabeled serial sections through the entire FL volume at P28. GBP treatment significantly reduced FL-induced increases in GFAP immunolabeling (Fig. 2A,D; 9.47\% \pm 1.24 GFAP+ pixels, $n=5$ animals) compared to vehicle treated FL animals $\left(26.23 \% \pm 6.97, n=5\right.$ animals; one-way ANOVA, $F_{(3)}=$ $6.73, p=0.004$; post hoc Bonferroni test, $\alpha=0.05$ ). Similarly, genetic deletion of $\alpha 2 \delta-1$ KO reduced GFAP immunolabeling after FL (Fig. 2A,D; 2.92\% $\pm 0.74, n=4$; post hoc Bonferroni test, $\alpha=0.01$ ) without any additive effects of GBP treatment $(6.77 \% \pm 2.36, n=4)$. Consistent with previous findings, these results show that GBP treatment reduces astrocyte reactivity via its actions on $\alpha 2 \delta-1$.

\section{FL induces $\alpha \mathbf{2} \delta$-1-dependent laminar reorganization of the cortex}

In order to better understand FL-induced anatomic changes, we examined the expression of layer specific markers in the cortex at P28. CUX1 and CTIP2 are transcription factors that preferentially label superficial (LII/III) and deep (LIV/VI) cortical layers, respectively (Insolera et al., 2014). Consistent with published data, CTIP2+ cells are abundant in deep cortical layers (Fig. $3 A ; 588 \pm 52$ per $\mathrm{mm}^{2}, n=11$ sections from four animals), and found sporadically in outer layers (Fig. $3 A ; 26 \pm 5$ per $\mathrm{mm}^{2}$ ) in the sham-injured cortex. Conversely, CUX1+ cells are more abundant in the outer layers and are sparser in deep layers (Fig. $3 A ; 743 \pm 31$ vs $119 \pm 26$ per $\mathrm{mm}^{2}$ ). In contrast to the normal six-layered cortex, FL creates a four-layered MZ. Layer $i$ is continuous with cortical Layer I (lower case $=$ FL nomenclature, upper case $=$ standard cortical layer nomenclature), and is the superficial most layer. It is thin and contains few cell bodies. Layer ii is neuron-rich and makes up the bulk of the MZ (Dvorák and Feit, 1977) and contains many cell bodies. Layer iii is a neuron-free area, and makes a clear border between superficial and deep cortical layers. Layer iv is identified as the deepest layer of cell bodies above the white matter. We defined layer $i$ and ii as the superficial layers of the MZ, and layer iv as the deep layer. Studies postulate that neurons in MZ layer ii are similar to Layer II/III neurons and that Layer IV-VI cortical neurons are lost, but the expression of layer-specific markers following FL has not been examined. We found that layer ii of the MZ is predominately composed of CUX1+ cells and layer iv of CTIP2+ cells, in line with previous predictions. Interestingly, there is a decreased density of CUX1+ cells in MZ layer ii (Fig. $3 A, B ; 285 \pm 34$ per $\mathrm{mm}^{2}, n=7$ sections from three animals; $t$ test, $t_{(16)}=9.40, p<0.001$, compared to sham-injured Layer II/III; Holm-Bonferroni correction for multiple comparisons, $\alpha=0.001$ ) and CTIP2 + cells in MZ layer iv (Fig. $3 A, C ; 240 \pm 31$ per $\mathrm{mm}^{2} ; t$ test, $t_{(15)}=6.47$, $p<0.001$, compared to Layer $\mathrm{V}-\mathrm{Vl}$; Holm-Bonferroni correction for multiple comparisons, $\alpha=0.001$ ). Additionally, the ratio of superficial layer (layer ii or II/III) to deep layer (iv or $\mathrm{VVI}$ ) is significantly higher in FL MZ cortex (Fig. 3D; $7.26 \pm 1.87, n=7$ sections from three animals) compared to sham-injured cortex (1.12 $\pm 0.06, n=11$ sections from four animals; $t$ test, $t_{(16)}=-4.17, p<0.001$; Holm-Bonferroni correction for multiple comparisons, $\alpha=$ 0.001 ) reflecting the loss of deep layer cells and concurrent expansion of the outer layer in FL cortex.

Based on these findings, we next examined how attenuating $\alpha 2 \delta$-1 signaling affects layer-specific changes in 
A 6 layer cortex

6 layer paramicrogyrial zone
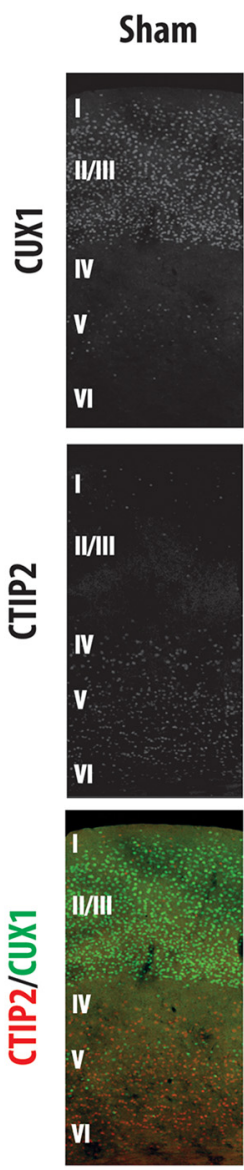

FL WT
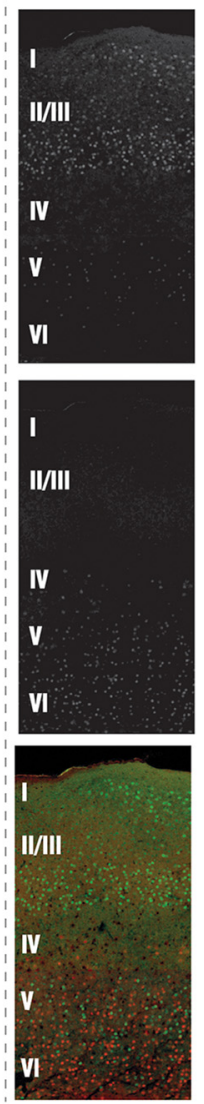
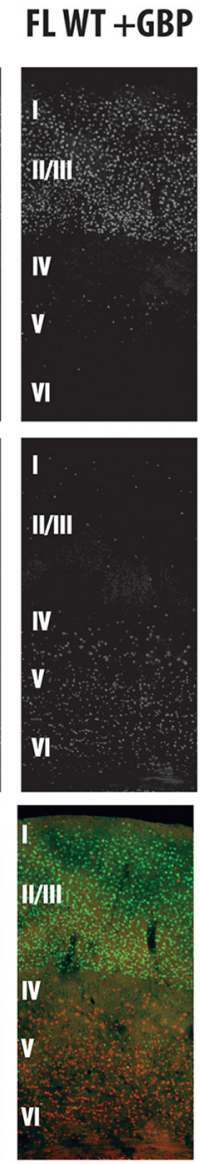

FL KO
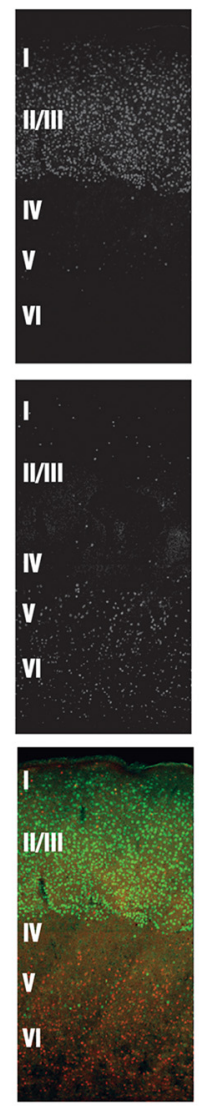

\section{4 layer microgyrial zone}

FL WT

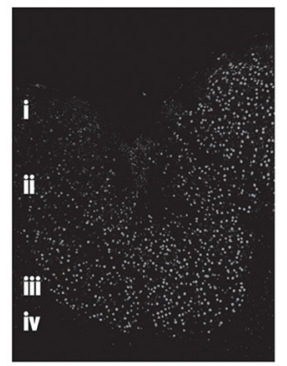

FL WT + GBP
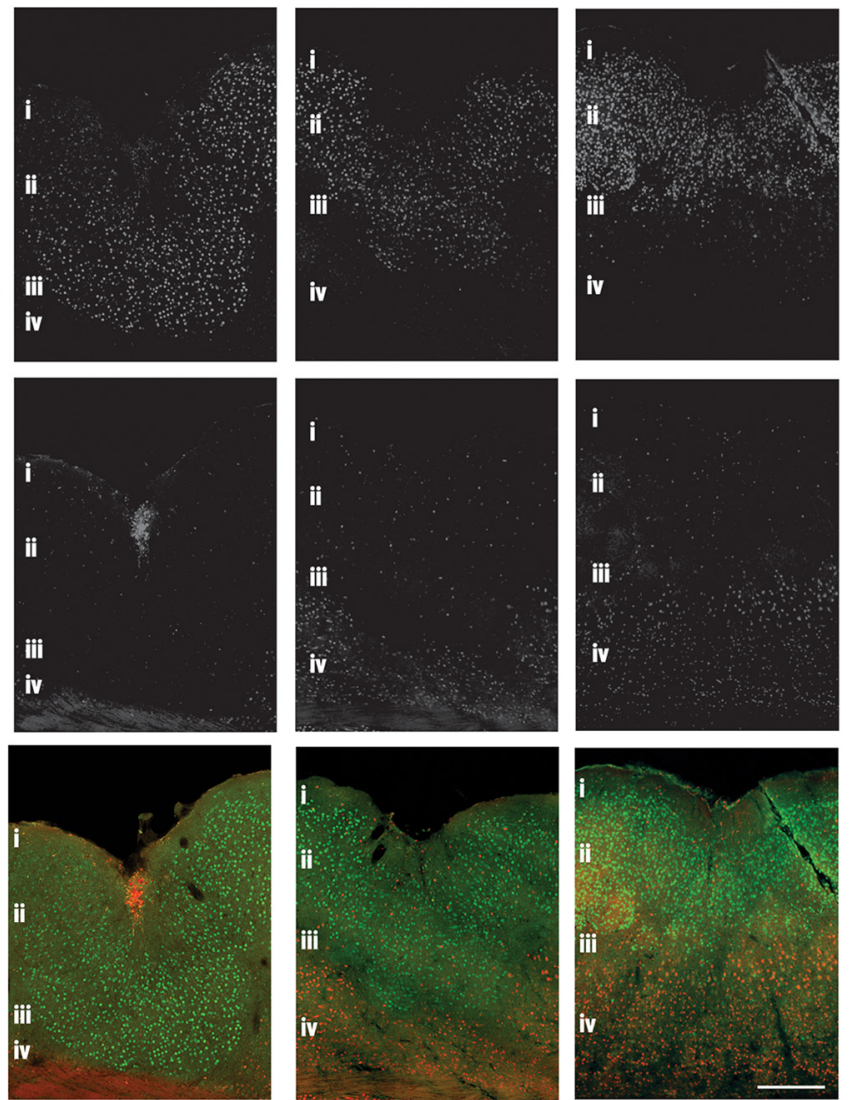

B

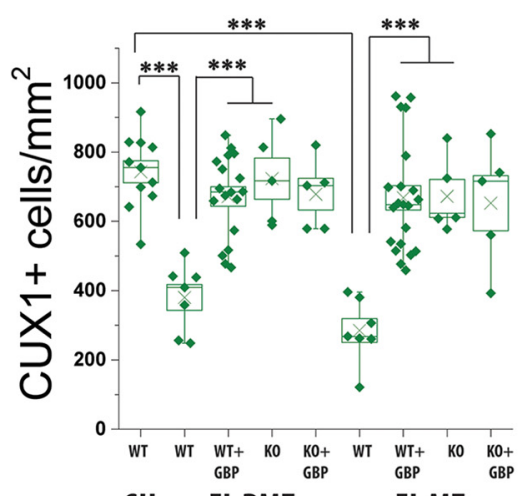

C

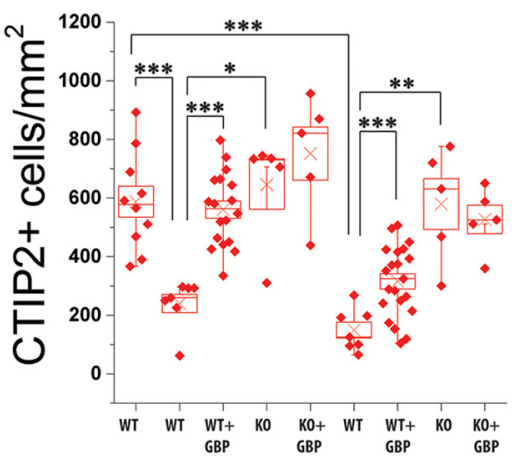

SH FL PMZ

\section{Deep Layers}

FL MZ

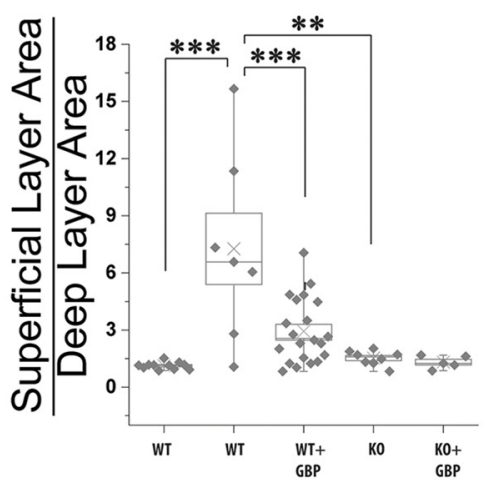

SH FL MZ

Figure 3. GBP treatment or $\alpha 2 \delta-1 \mathrm{KO}$ attenuates the loss of layer-specific markers in the FL cortex. $\boldsymbol{A}$, Representative images of CUX1 (green) and CTIP2 (red) staining in P28 WT sham cortex and the PMZ and MZ of WT FL, WT FL + GBP, and $\alpha 2 \delta-1^{-/-}$(KO) FL cortex. Scale bar $=250 \mu \mathrm{m}$. B , Box-whisker plot of CUX1+ cells per $\mathrm{mm}^{2}$ in the outer layers, $* * * \alpha=0.001$ (Holm-Bonferroni multiplecomparison correction). $\boldsymbol{C}$, Box-whisker plot of CTIP2+ cells per $\mathrm{mm}^{2}$ in the deep layers, $* * * \alpha=0.001, * * \alpha=0.01$, and $* \alpha=0.05$ (Holm-Bonferroni multiple-comparison correction). $\boldsymbol{D}$, Box-whisker plot of ratio of area of outer layer (Layer II/III in sham and layer ii in $\mathrm{FL}$ ) to area of inner layer (Layer $\mathrm{V}$ and $\mathrm{VI}$ in sham and layer iv in $\mathrm{FL}$ ) in sham, $\mathrm{FL}, \mathrm{FL}+\mathrm{GBP}$, and $\alpha 2 \delta-1 \mathrm{KO} F L$ cortex, $* * * \alpha=0.001$ and $* * \alpha=0.01$ (Holm-Bonferroni multiple-comparison correction).

the MZ. Sham and FL animals were treated with GBP, as described above, and CTIP2+ and CUX1+ cells were identified at P28. GBP treatment restored the density of
CUX1+ cells in the outer layers to sham-injured levels (Fig. $3 A, B ; 668 \pm 32$ per $\mathrm{mm}^{2}, n=21$ sections from four animals; Mann-Whitney, $U_{(23)}=0, p<0.001$, compared 
to vehicle-treated FL; Holm-Bonferroni correction for multiple comparisons, $\alpha=0.001$ ) and significantly increased the density of deep layer CTIP2+ cells (Fig. 3A,C; $111 \pm$ 14 per $\mathrm{mm}^{2}$; $t$ test, $t_{(26)}=-3.43, p<0.001$, compared to vehicle-treated FL; Holm-Bonferroni correction for multiple comparisons, $\alpha=0.001$ ). Consistent with a significant reduction of lesion volume, FL animals treated with GBP have a significantly smaller superficial/deep layer ratio of $2.93 \pm 0.37$ (Fig. $3 D ; n=21$ sections from four animals; $t$ test, $t_{(26)}=3.53, p<0.001$; Holm-Bonferroni correction for multiple comparisons, $\alpha=0.001$ ) and the MZ more closely resembles the normal six-layered cortex.

We next examined how genetic deletion of $\alpha 2 \delta$-1 affected laminar reorganization in the MZ. $\alpha 2 \delta-1 \mathrm{KO}$ attenuated FL-induced decreases in CUX1+ and CTIP2 + cell density (Fig. $3 A-C ; 723 \pm 59, n=5$ sections from three animals; $t$ test, $t_{(10)}=-6.68, p<0.001$; Holm-Bonferroni correction for multiple comparisons, $\alpha=0.001$ and $646 \pm$ 84 cells per $\mathrm{mm}^{2}$; $t$ test, $t_{(8)}=-6.68, p<0.001$, compared to WT FL; Holm-Bonferroni correction for multiple comparisons, $\alpha=0.01)$. FL-induced changes in the ratio of superficial/deep layers were also significantly attenuated in $\alpha 2 \delta-1 \mathrm{KO}$ animals (Fig. 3D; $1.52 \pm 0.13, n=8$ sections from three animals; $t$ test, $t_{(17)}=-3.00, p<$ 0.001; Holm-Bonferroni correction for multiple comparisons, $\alpha=0.01)$. GBP-treatment did not affect CUX1+ and CTIP2 + cell density in $\alpha 2 \delta$-1 KO mice (Fig. $3 A-C$; $692 \pm 81$ and $676 \pm 103$ cells per $\mathrm{mm}^{2}, n=7$ sections from three animals).

We next examined the cellular density of CUX1 and CTIP2 in the PMZ, the area immediately adjacent to the $M Z$, which is responsible for generating epileptiform network activity. Interestingly, the PMZ has long been considered an area of normal cortical lamination. While gross cortical lamination is normal, we found that FL alters the density of CUX1+ and CTIP2+ cells in the PMZ. The density of CUX1+ cells in superficial layers (Fig. $3 A, B$; $380 \pm 37$ cells per $\mathrm{mm}^{2} ; t$ test, $t_{(16)}=9.40, p<0.001$; Holm-Bonferroni correction for multiple comparisons, $\alpha=$ 0.001 ) and density of CTIP2 + cells in deep layers (Fig. $3 A, C ; 240 \pm 31$ cells per $\mathrm{mm}^{2}$; Mann-Whitney, $U_{(16)}=70$, $p=0.0001$; Holm-Bonferroni correction for multiple comparisons, $\alpha=0.001$ ) were significantly reduced in the PMZ as compared to sham-injured cortex. GBP treatment prevented the layer-specific decreases in CUX1+ and CTIP2 + cells in the PMZ $(671 \pm 28$; Mann-Whitney, $U_{(23)}=0, p<0.001$; Holm-Bonferroni correction for multiple comparisons, $\alpha=0.001$ and $560 \pm 29$ cells per $\mathrm{mm}^{2}$; Mann-Whitney, $U_{(23)}=0, p<0.001$; HolmBonferroni correction for multiple comparisons, $\alpha=$ 0.001 , respectively), as does $\alpha 2 \delta-1 \mathrm{KO}(672 \pm 48$; $t$ test, $t_{(10)}=-5.16, p=0.0004$ and $579 \pm 86$ cells per $\mathrm{mm}^{2}$; Mann-Whitney, $U_{(10)}=0, p=0.006$; Holm-Bonferroni correction for multiple comparisons, $\alpha=0.05$ ). GBP treatment did not provide further protection against anatomic reorganization, again suggesting GBP mediates it protective effects via $\alpha 2 \delta-1$. These results demonstrate that FL disrupts cortical lamination via $\alpha 2 \delta-1$ signaling, as assayed by the expression of layer-specific markers.

\section{Total neuron number is normal in the FL cortex}

Because the expression of CUX1 and CTIP2 was altered by FL, we wondered whether neuronal density was also affected. To test this, we performed NeuN staining and counted the total number of neurons in the cortex. Confocal images of the outer and deep cortical layer were used to determine neuronal density, in sham-injured cortex and in the MZ and PMZ of the FL cortex. In comparison to the dramatic changes found in CUX1 and CTIP2 staining following $\mathrm{FL}$, no significant reduction in total neuron number was observed (data not shown). These results suggest that overall neuronal density is normal in the FL cortex at P28, despite changes in CUX1+ and CTIP2+ cell density.

\section{Decreasing $\alpha \mathbf{2 \delta}$-1 signaling attenuates FL-driven increases in synaptogenesis}

GBP decreases excitatory synaptogenesis during development (Eroglu et al., 2009) and following injury ( $\mathrm{Li}$ et al., 2012; Li et al., 2014). We have previously shown that GBP treatment can block FL-induced cortical network hyperexcitability and increased EPSC frequency (Andresen et al., 2014). We hypothesized that hyperexcitability was prevented by attenuating $\alpha 2 \delta$-1-driven aberrant excitatory synaptogenesis in the FL cortex. Here, we examined excitatory synapse number by immunolabeling with the pre- and postsynaptic markers, VGLUT1 and PSD95. Synapse counting was performed at P28 in Layer V adjacent to the injury (PMZ), as this is the region that was previously shown to be hyperexcitable and to have increased excitatory synaptic activity following FL. Colocalization of VGLUT1 and PSD95 puncta was quantified (Ippolito and Eroglu, 2010) to determine the density of putative excitatory synaptic contacts. We found that sham-injured WT animals had a synaptic density of $488 \pm$ 70 per $0.1 \mathrm{~mm}^{2}$ ( $n=8$ sections from three animals; Fig. 4). $\mathrm{FL}$ induced a marked increase in the density of putative excitatory synapses in WT mice (Fig. 4A,B; $758 \pm 68$ per $0.1 \mathrm{~mm}^{2}, n=7$ sections from three animals; MannWhitney, $U_{(13)}=3, p<0.001$ compared to WT sham; Holm-Bonferroni correction for multiple comparisons, $\alpha=$ 0.001). Both GBP treatment and genetic deletion of $\alpha 2 \delta-1$ attenuated FL-induced increase in colocalized VGLUT1/ PSD95 puncta (Fig. 4A,B; $567 \pm 41, n=7$ sections from three animals; $t$ test, $t_{(16)}=3.50, p=0.0029$; HolmBonferroni correction for multiple comparisons, $\alpha=0.01$ and $556 \pm 60, n=9$ sections from three animals; $t$ test, $t_{(22)}=3.55, p=0.0018$ compared to WT FL; HolmBonferroni correction for multiple comparisons, $\alpha=0.01$ ). In contrast to our other results, GBP treatment further reduced synapse number in the FL $\alpha 2 \delta-1 \mathrm{KO}$ mice (368 \pm 45 per $0.1 \mathrm{~mm}^{2}, n=8$ sections from three animals, $t$ test, $t_{(19)}=3.28, p=0.004$; Holm-Bonferroni correction for multiple comparisons, $\alpha=0.01$ ). These results demonstrate that FL induces $\alpha 2 \delta$-1-mediated synaptogenesis, but that GBP also has $\alpha 2 \delta$-1-independent effects on synaptogenesis. 
A

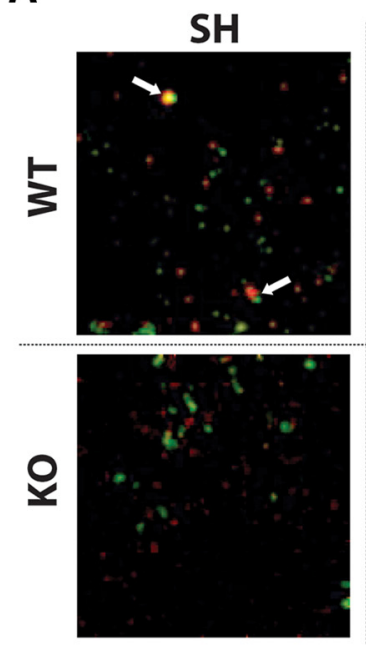

FL
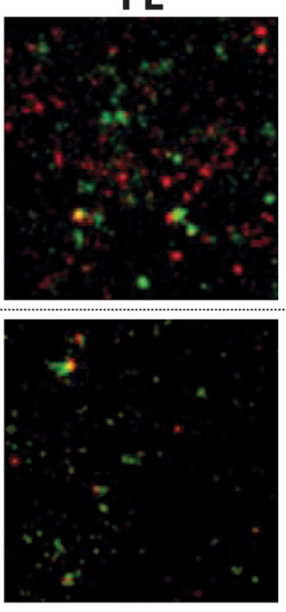

FL+GBP
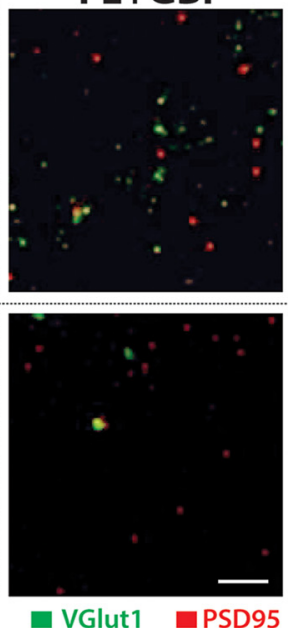

B

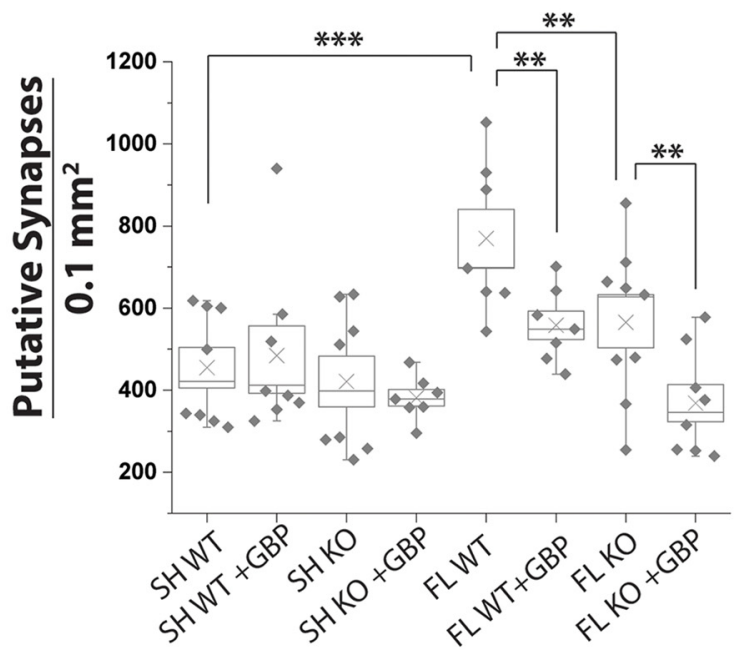

Figure 4. GBP treatment or $\alpha 2 \delta$-1 deletion decreases FL-driven synaptogenesis. $\boldsymbol{A}$, MIPs from of three optical sections of confocal images of VGlut1 (green) and PSD95 (red) collected at 100 $\times$ from Layer V of WT and $\alpha 2 \delta-1^{-1-}$ (KO) FL and sham-injured animals, with vehicle or GBP treatment. White arrow indicates colocalization of VGLUT1 and PSD95, representing a site of synaptic contact. Scale bar $=500 \mathrm{~nm}$. B, Box-whisker plot of number of synapses (colocalization of VGlut1/PSD95) per $1.00 \mathrm{~mm}^{3}$ per MIP, $* * \alpha=0.01$ and $* * * \alpha=0.001$ (Holm-Bonferroni multiple-comparison correction).

\section{Attenuating $\alpha 2 \delta$-1 signaling inhibits FL-driven increases in synaptic excitation}

Given the changes in excitatory synapse number, we next assessed the role of $\alpha 2 \delta$-1 signaling on synaptic excitation by examining mEPSCs in the FL cortex. mEPSCs were recorded from Layer $V$ pyramidal neurons $\sim 200$ $\mu \mathrm{m}$ from the site of injury in the PMZ of FL animals, or comparable cortical area in sham-injured animals. Neurons were held at $-70 \mathrm{mV}$ and perfused with normal aCSF containing $1 \mu \mathrm{m}$ TTX. We found no significant differences in resting membrane potential, rise or decay kinetics, or the amplitude of the mEPSC events between groups (Fig. $5 B$ ). Similar to our previous study (Andresen et al., 2014), we found that $\mathrm{FL}$ induced a rise in $\mathrm{MEPSC}$ frequency (Fig. $5 A, C ; 0.79 \pm 0.19 \mathrm{~Hz}, n=14$ cells from three animals; Mann-Whitney, $U_{(20)}=22.5, p=0.002$; Holm-Bonferroni correction for multiple comparisons, $\alpha=0.05$ ) compared to sham-injured animals $(0.23 \pm 0.05 \mathrm{~Hz}, n=8$ cells from three animals). GBP treatment significantly reduced the mEPSC frequency $(0.29 \pm 0.09 \mathrm{~Hz}, n=13$ cells from three animals; Mann-Whitney, $U_{(25)}=142.5, p=0.013$; Holm-Bonferroni correction for multiple comparisons, $\alpha=$ $0.05) . \alpha 2 \delta$ - 1 deletion led to a non-significant reduction in mean mEPSC frequency $(0.30 \pm 0.04 \mathrm{~Hz}, n=10$ cells from three animals; Mann-Whitney, $U_{(22)}=103, p=$ $0.055)$ following FL. GBP treatment had no effect on mEPSC frequency in $\alpha 2 \delta-1 \mathrm{KO}$ mice. The cumulative probability distribution of the interevent interval (IEI) was also calculated to more rigorously assess changes in mEPSC frequency. The leftward shift in the IEl cumulative probability in WT FL cortex, compared to WT sham, shows an increased frequency of excitatory synaptic events following FL (Fig. $5 D$; KS test, $D_{(21)}=0.71, p=0.0002$; Holm-Bonferroni correction for multiple comparisons, $\alpha=$ 0.001 . The IEI cumulative probability is shifted rightward in both GBP treated WT FL and $\alpha 2 \delta-1 \mathrm{KO} F L$ animals (KS test, $D_{(26)}=0.82, p=0.0001$ and KS test, $D_{(22)}=0.64$, $p=0.0009$ compared to WT FL; Holm-Bonferroni correction for multiple comparisons, $\alpha=0.001$ ), demonstrating that both GBP treatment and $\alpha 2 \delta-1$ deletion reduces synaptic excitation.

\section{Genetic deletion of $\alpha \mathbf{2} \delta$-1 attenuates FL-driven network hyperexcitability}

Epileptiform activity can be readily evoked in the adult FL cortex (Jacobs et al., 1996; Luhmann et al., 1996; Jacobs et al., 1999). In a previous study, we showed that GBP treatment prevents the development of evoked epileptiform field EPSCs (fEPSPs) recorded from acute cortical slices (Andresen et al., 2014). Given that $\alpha 2 \delta$-1 deletion prevents FL-induced excitatory synaptogenesis, we hypothesized that $\alpha 2 \delta-1 \mathrm{KO}$ would also decrease network hyperexcitability. To test this hypothesis, fEPSPs were evoked by stimulating the white matter beneath the cortex and recording from Layer $V$ of the PMZ. Stimulation intensity was set as the minimum stimulation required to elicit a detectable response, and did not differ significantly between groups. We quantified the number of sweeps per slice with epileptiform activity (defined by high frequency activity, as well as increased amplitude and duration) and the integrated area under the curve of the fEPSP response. Slices from WT sham-injured animals show almost no epileptiform activity (Fig. 6B; $1 \%, n=16$ sections from four animals) and a small fEPSP area (Fig. 6C; $14.48 \pm 1.75 \mathrm{mV} * \mathrm{~ms})$. Similar to previous studies, we found that $\mathrm{FL}$ animals have robust epileptiform activity (Fig. 6A,B; $76.6 \pm 9 \%, n=18$ sections from four animals, Mann-Whitney, $U_{(33)}=32, p<0.001$; Holm-Bonferroni correction for multiple comparisons, $\alpha=0.001$ ), corresponding to a significantly larger fEPSP area (Fig. 6C; 
A

SH WT
B

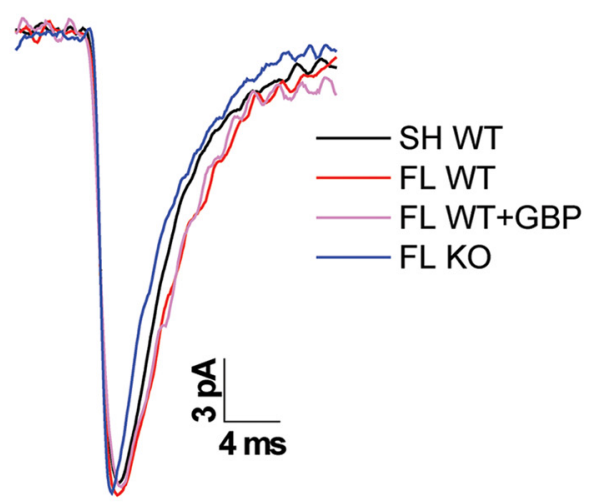

FL KO

\section{$40 \mathrm{pA}$}

$1 \mathrm{sec}$

C

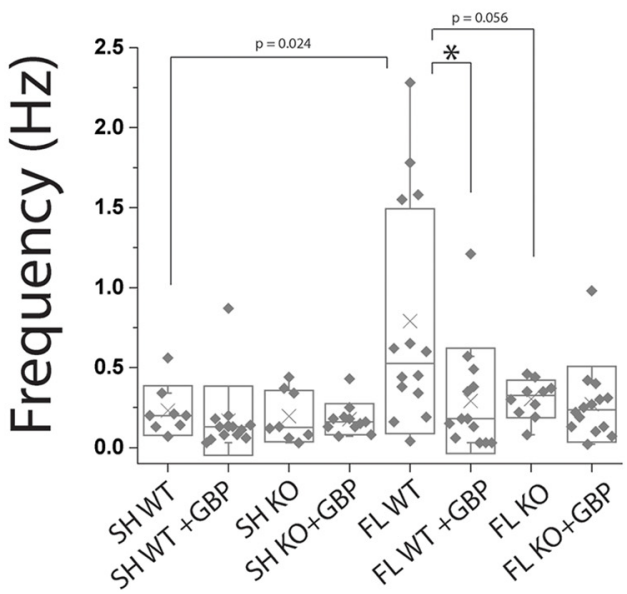

D

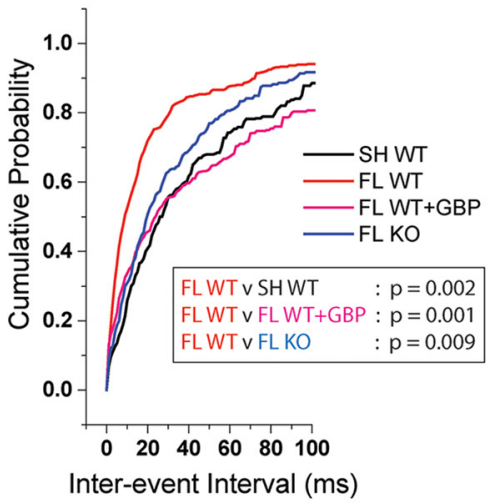

Figure 5. GBP treatment or $\alpha 2 \delta-1 \mathrm{KO}$ attenuates the rise in mEPSC frequency in the FL cortex. $\boldsymbol{A}$, Representative miniature excitatory postsynaptic current recording of Layer $\mathrm{V}$ pyramidal neuron recorded from the PMZ of acute cortical slices prepared from P21 to P28 WT sham, WT FL, WT FL + GBP, and $\alpha 2 \delta-1^{-1-}$ (KO) FL. B, Example mEPSC from WT sham (black), WT FL (red), WT FL + GBP (pink), and $\alpha 2 \delta-1^{-1-} \mathrm{FL}$ (blue). C. Box-whisker plot of frequency of mEPSC events, $* \alpha=0.05$ (Holm-Bonferroni multiple-comparison correction). $\boldsymbol{D}$, Cumulative probability of IEls of WT sham (black), WT FL (red), WT FL + GBP (pink), and $\alpha 2 \delta^{-1} 1^{-/-}$FL (blue). WT FL has a significant rightward shift compared to WT sham, WT FL + GBP, and $\alpha 2 \delta-1^{-/-} \mathrm{FL}, p<0.001$ (KS test).

$47.35 \pm 7.33 \mathrm{mV} * \mathrm{~ms}$, Mann-Whitney, $U_{(33)}=37, p<$ 0.001; Holm-Bonferroni correction for multiple comparisons, $\alpha=0.001)$. GBP treatment significantly decreased the percentage epileptiform activity (Fig. $6 A, B ; 16.6 \pm$ $7 \%, n=12$ section from three animals; Mann-Whitney, $U_{(28)}=191.5, p<0.001$; Holm-Bonferroni correction for multiple comparisons, $\alpha=0.001$ ) and fEPSP area (Fig. $6 C$; $13.02 \pm 3.59 \mathrm{mV} * \mathrm{~ms}$; Mann-Whitney, $U_{(28)}=193, p<$ 0.001 ; Holm-Bonferroni correction for multiple comparisons, $p<0.01$ ) following FL. Genetic deletion of $\alpha 2 \delta-1$ caused a non-significant trend toward decreased epileptiform activity following $\mathrm{FL}$ (Fig. $6 A, B ; 47.1 \pm 10 \%, n=20$ sections from three animals; Mann-Whitney, $U_{(36)}=$ 240.5, $p=0.06$ ), and significantly decreased fEPSP area (Fig. 6C; $26.92 \pm 4.14 \mathrm{mV} * \mathrm{~ms}$; Mann-Whitney, $U_{(36)}=$ 262, $p=0.017$; Holm-Bonferroni correction for multiple comparisons, $\alpha=0.05)$ compared to WT FL. GBP treatment had no additive effect in $\alpha 2 \delta-1 \mathrm{KO}$ animals after $\mathrm{FL}$ on percentage epileptiform activity (Fig. 6A,B; $40.0 \pm$
$14.3 \%, n=12$ sections from three animals) or fEPSP area (Fig. 6C; $26.95 \pm 5.95 \mathrm{mV} * \mathrm{~ms}$ ) compared to vehicletreated FL $\alpha 2 \delta-1$ KOs suggesting that the actions of GBP on network hyperexcitability are specific to antagonizing $\alpha 2 \delta-1$ signaling. These results suggest an intermediate effect of $\alpha 2 \delta$-1 deletion compared to acute pharmacological attenuation of $\alpha 2 \delta-1$ on network hyperexcitability.

\section{Linear mixed effects modeling of data to increase statistical rigor}

Based on the call to increase rigor and reproducibility in preclinical studies, we performed a more advanced statistical analysis of all our results. The goal of this secondary level of analysis was to identify results that may require further studies to ensure their robustness and reproducibility. We employed a linear mixed effects model (Laird and Ware, 1982) that (1) includes mouse-specific random intercepts to account for correlation due to multiple measures in the same mouse, (2) allows us to look at 
A SH WT

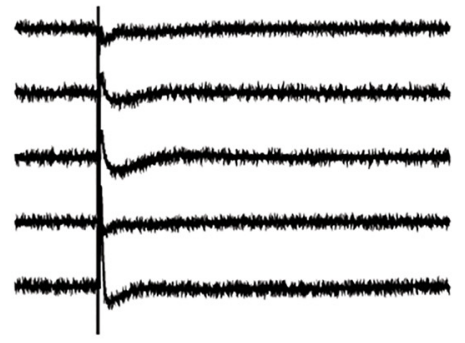

SH KO

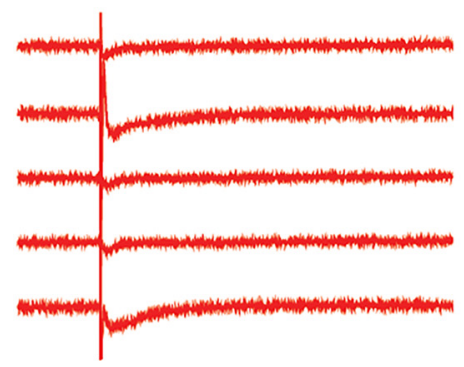

FL WT

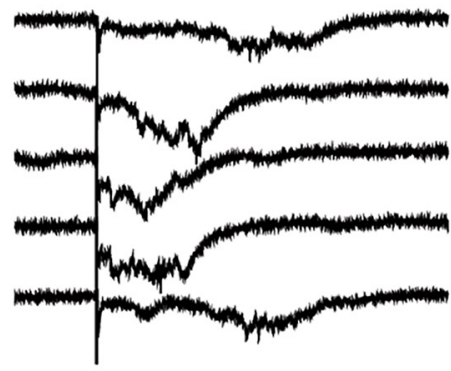

FL KO

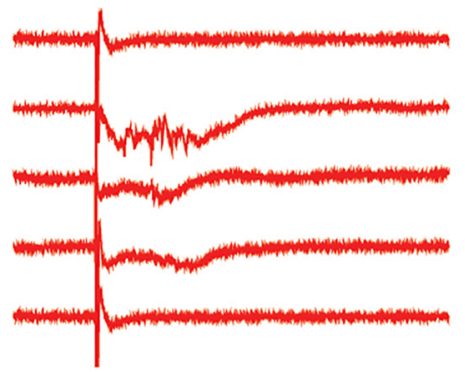

FL WT+GBP

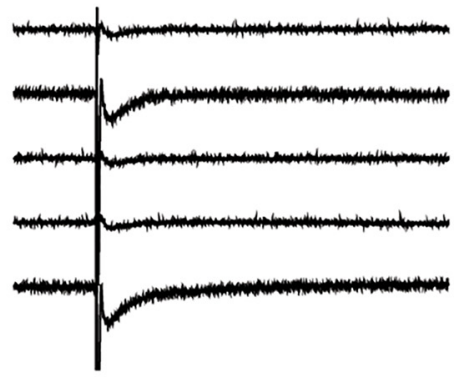

FL KO+GBP

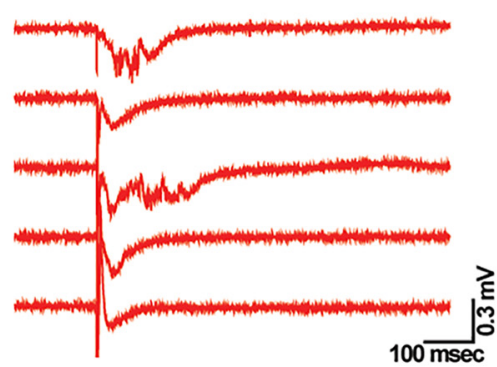

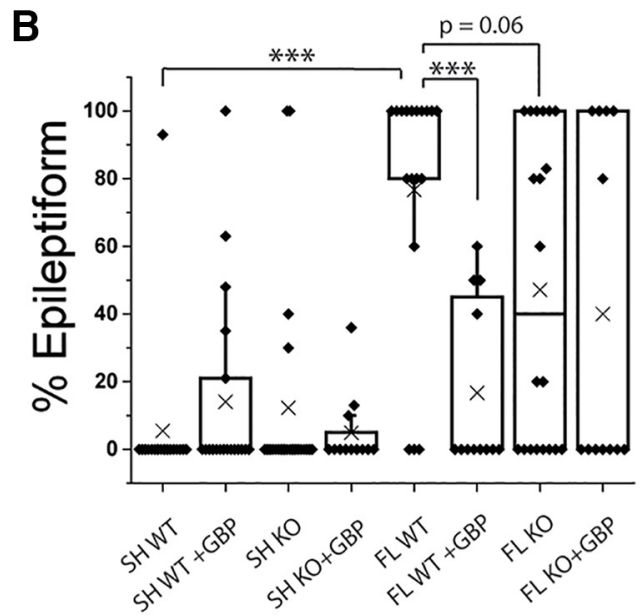

C

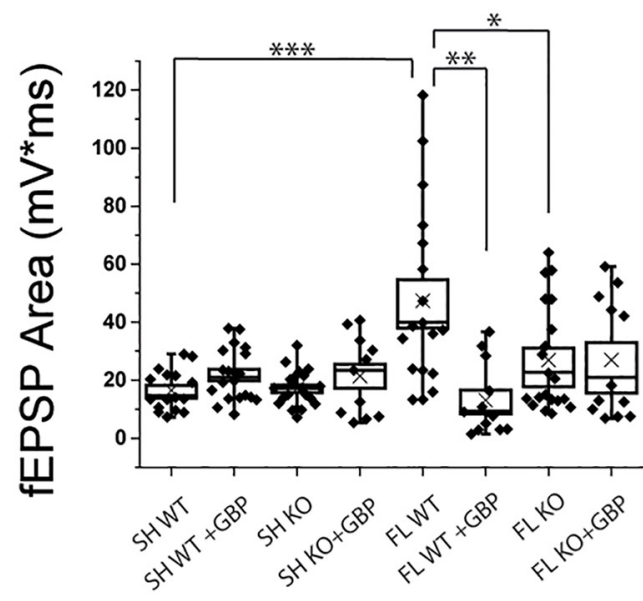

Figure 6. $\alpha 2 \delta-1 \mathrm{KO}$ partially rescues network hyperexcitability following FL and is insensitive to GBP treatment. $\boldsymbol{A}$, Representative evoked cortical field EPSP traces recorded from the PMZ of acute cortical slices prepared from P21 to P28 WT sham, $\alpha 2 \delta^{-1} 1^{-1-}$ sham, WT FL, $\alpha 2 \delta-1^{-1-}$ FL, WT FL + GBP, and $\alpha 2 \delta-1^{-1-}$ FL + GBP animals. B, Box-whisker plot of percentage epileptiform sweeps per slice, $* * * \alpha=0.001$ (Holm-Bonferroni multiple-comparison correction). $\boldsymbol{C}$, Box-whisker plot of integrated area under the curve per slice, $* \alpha=0.05, * * \alpha=0.01$, and $* \alpha=0.05$ (Holm-Bonferroni multiple-comparison correction).

the interactions between manipulations (FL, drug treatment, and genetic manipulation), and (3) encompasses the entire study design within a single statistical approach. For all studies described above, regression coefficients from the linear mixed-effects models were calculated (Table 1) and indicate the degree to which different experimental conditions alter the mean outcomes for each assay. The GBP main effect, for example, measures the change in mean outcome after GBP treatment specifically in sham-injured WT mice, though the effect also applies to all experimental groups that received GBP. The FL/GBP interaction term, on the other hand, measures the additional difference in the effect of
GBP in FL versus sham-injured mice. Results varied by experiment, but generally agree with statistical analysis performed using Student's $t$ test/Mann-Whitney tests with a Bonferroni correction for repeated measures. The most robust effects based on linear mixed effects modeling were the (1) FL main effect, and the interactions among (2) FL/GBP, (3) FL/KO, and (4) GBP/KO. This indicates that (1) FL has robust effect across assays, (2/3) GBP and $\alpha 2 \delta-1 \mathrm{KO}$ have important effects in $\mathrm{FL}$ animals, and that (4) the effects of GBP are largely lost in $\alpha 2 \delta-1 \mathrm{KO}$ mice. Importantly, there are some results that have less statistical significance based on the linear mixed effects model. Less robust results include the effects of $\alpha 2 \delta-1 \mathrm{KO}$ on 
Table 1. Linear mixed effects modeling table of coefficient, SE, and $t$ value calculated from the linear mixed effect model for data from: TUNEL assay (Fig. 1), caspase-3 staining (Fig. 1), CUX1 and CTIP2 staining (Fig. 3), superficial/deep layer area ratio (Fig. 3), synapse counting (Fig. 4), fEPSP \%epileptiform (Fig. 6), and fEPSP area (Fig. 6)

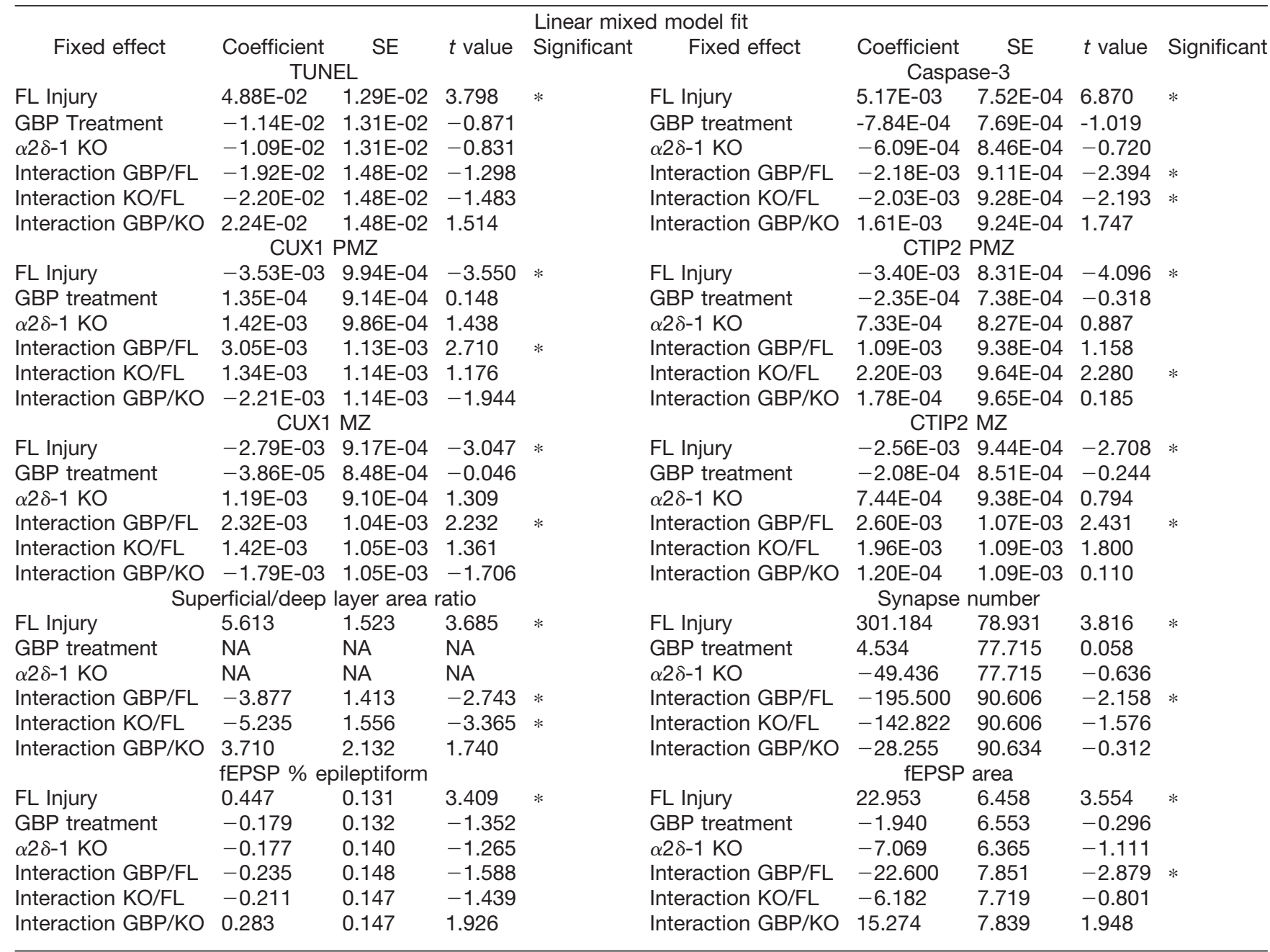

*t value $>1.96$ or $<-1.96$.

circuit hyperexcitability after FL, the effects of GBP treatment on the recovery of CTIP2, and the effects of $\alpha 2 \delta-1$ $\mathrm{KO}$ on the recovery of CUX1. These specific findings may warrant further study to ensure their robustness before moving forward with any clinical applications. In general, this additional statistical analysis shows that GBP and $\alpha 2 \delta$ - 1 have robust effects across multiple FL-associated pathologies.

\section{Discussion}

Treatment with GBP, a clinically used anticonvulsant and antagonist of $\alpha 2 \delta$-1, attenuates pathologic changes following experimental neonatal and adult brain insult (Traa et al., 2008; Li et al., 2012; Andresen et al., 2014). $\alpha 2 \delta$-1 (a calcium channel auxiliary subunit) and its synaptogenic ligand, TSP, are increased following brain trauma, suggesting injury-induced activation of $\alpha 2 \delta-1$ signaling. Defining the precise role of $\alpha 2 \delta$-1 in the pathology of brain injury has been difficult, however, as GBP is known to directly bind to both $\alpha 2 \delta-1$ and $\alpha 2 \delta-2$, and has indirect effects on other systems (NMDA receptors; Kim et al.,
2009), sodium channels (Yang et al., 2009), and protein kinase C (Maneuf and McKnight, 2001; Yeh et al., 2011). Here, we used mice lacking $\alpha 2 \delta$ - 1 to establish its role in pathology associated with FL, and to determine the site of action of GBP's neuroprotective effects. We show, for the first time, that $\alpha 2 \delta-1$ plays a direct role in cell death, anatomic reorganization, synaptogenesis, astrocytosis, expression of layer-specific cortical markers, and network hyperexcitability in the FL model of cortical malformation. By genetically deleting $\alpha 2 \delta-1$, we established that it mediates GBP's neuroprotective effects. Our findings show $\alpha 2 \delta-1$ has an important role in injury-induced cell death and synaptogenesis, and suggest that $\alpha 2 \delta$-1 activity may be involved with pathogenesis associated with acquired DCMs.

GBP treatment is neuroprotective in models of cortical deafferenation (Li et al., 2012), neonatal ischemia (Traa et al., 2008), and ischemic brain injury (Williams et al., 2006), likely due to attenuation of TSP $/ \alpha 2 \delta-1$ signaling. Human studies show elevated TSP-1 in plasma after head 
trauma (Wang et al., 2016), human endothelial cells upregulate TSP-1 after oxidative stress (Ning et al., 2011), and TSP1 and TSP2 are increased in rodent models of stroke (Lin et al., 2003). Likewise, $\alpha 2 \delta-1$ expression is upregulated in injury models in both the central and peripheral nervous system (Boroujerdi et al., 2008; Li et al., 2012; Andresen et al., 2014), leading to an overabundance of both ligand and receptor. Beyond changes in expression, $\alpha 2 \delta$-1's subcellular localization is altered in areas of neuronal death following chemoconvulsive seizures (Nieto-Rostro et al., 2014), suggesting subtle changes in $\alpha 2 \delta$-1 signaling may be relevant to cell death and epileptogenesis.

How $\alpha 2 \delta-1$ signaling leads to cell death is not clear, but calcium-dependent caspase-mediated apoptosis, appears to be involved. Loss of $\alpha 2 \delta-1$ decreases the duration of calcium channel currents in cardiac myocytes (Fuller-Bicer et al., 2009) and calcium channel density (Patel et al., 2013) in sensory neurons. Conversely, over expression of $\alpha 2 \delta-1$ increases neurotransmitter release following action potential firing in the hippocampus (Hoppa et al., 2012), which could leader to greater excitation. We see two ways in which $\alpha 2 \delta-1$ might contribute to injury-induced cell death. First, by increasing excitatory synapse formation and enhancing excitation, $\alpha 2 \delta-1$ activity likely potentiates glutamate-induced excitotoxicity. Second, by enhancing calcium currents and intracellular calcium levels, $\alpha 2 \delta-1$ may promote caspase activation. Both aspects of $\alpha 2 \delta-1$ may contribute to lesion-induced cell death, and undoubtedly occur in parallel with other forms of cell death that do not involve $\alpha 2 \delta-1$. Future studies will be required to identify which aspects of $\alpha 2 \delta-1$ function lead to injury-induced cell death and if certain cell types are more vulnerable to $\alpha 2 \delta$ 1-mediated cell death.

In addition to driving cell death, FL also induces robust astrocytosis (Bordey et al., 2001; Campbell and Hablitz, 2008; Dulla et al., 2013; Armbruster et al., 2014). Here, we show that $\alpha 2 \delta-1$ signaling plays an important role in driving reactive astrocytosis. GFAP immunoreactivity was greatly reduced by attenuating $\alpha 2 \delta-1$ signaling, and no additional effect of GBP was seen in $\alpha 2 \delta-1 \mathrm{KO}$ animals. Although astrocytes express $\alpha 2 \delta-1$ at a low-level, it is much more abundantly expressed by neurons (Zhang et al., 2014). This suggests that decreased astrocyte reactivity may be a secondary effect of reduced cell death and subsequent neuroinflammation, rather than a direct effect on $\alpha 2 \delta-1$ expressed by astrocytes. How $\alpha 2 \delta-1$ contributes more broadly to neuroinflammation, macrophage lineage cells, neuro-immune interactions, and cell death signaling warrants future investigation.

$\alpha 2 \delta$ - 1 activity following FL also promotes lesion formation and disrupts cortical lamination (shown by CUX1 and CTIP2 staining), in both the MZ and PMZ. Previous reports describe the neuronal architecture of the PMZ as normally laminated. Our results confirm that although gross level changes in cortical structure and total neuron number do not occur in the PMZ, more subtle differences may exist, as indicated by the reduction in the density of in CUX1+ and CTIP2+ neurons. How this change is linked to FL-induced pathologies is unknown. CTIP2 or
CUX1 are both transcription factors (Molyneaux et al., 2007; Sansregret and Nepveu, 2008) that control the expression of proteins related to neuronal morphologic development (Arlotta et al., 2005; Li et al., 2010). Whether changes in the density of CUX1+ and CTIP2 + neurons are associated with known changes in synaptic connectivity or neuronal morphology remains to be seen.

In addition to the established role of TSP $/ \alpha 2 \delta$ - 1 signaling in developmental synaptogenesis, our work also supports a role for $\alpha 2 \delta-1$ in pathologic synaptogenesis. $\alpha 2 \delta-1$ $\mathrm{KO}$ and in vivo treatment with GBP attenuated injuryinduced increases in both anatomic and functional synapses, in agreement with previous studies (Li et al., 2012; Andresen et al., 2014). Although functional synapses were not affected by GBP treatment in $\alpha 2 \delta-1 \mathrm{KO}$ mice, there was a minor reduction in the abundance of structural synapses. Other $\alpha 2 \delta$ subunits may mediate these effects. $\alpha 2 \delta-1, \alpha 2 \delta-2$, and $\alpha 2 \delta-3$ are all widely expressed in the CNS, with each isoform having a distinct distribution (Cole et al., 2005). Genetic deletion of $\alpha 2 \delta-1$ does not grossly alter the expression of other $\alpha 2 \delta$ isoforms (Fuller-Bicer et al., 2009), however, regional compensation or injuryspecific alterations may still exist and be relevant to FLinduced pathologies. GBP can bind to $\alpha 2 \delta-2$ (Gee et al., 1996) and $\alpha 2 \delta-3$ has been shown to play a synaptogenic role in drosophila (Kurshan et al., 2009). Taken together, these results suggest that other $\alpha 2 \delta$ isoforms may account for the GBP effect on synapse number in the $\alpha 2 \delta-1-\mathrm{KO}$ FL cortex. Additionally, it is unknown whether changes in other calcium channel auxiliary subunits occur following genetic deletion of $\alpha 2 \delta-1$ or neonatal injury. Also important to note, only vGlut1+ synapses, the predominant vGlut in the cortex, were quantified here. TSP $/ \alpha 2 \delta-1$ signaling drives the formation of vGlut2 containing synapses during normal development (Eroglu et al., 2009). Conversely, GBP treatment reduces injury-induced increases in vGlut1-containing excitatory synapses (Li et al., 2012). Our studies further support a role of $\alpha 2 \delta-1$ in driving vGlut1-containing synapse formation after injury, in addition to its role in driving vGlut2-containing synapses during development. This suggests injury increases intracortical excitation, mediated by vGlut1-containing synapses (Fremeau et al., 2004). Changes in vGlut2containing synapses, calcium channel trafficking (Hendrich et al., 2008), and homeostatic plasticity may underlie the discrepancy in the effects of GBP in $\alpha 2 \delta-1$ KOs on functional versus structural synapses.

Finally, inhibiting $\alpha 2 \delta-1$ signaling reduced cortical network hyperexcitability after FL. While genetic deletion of $\alpha 2 \delta-1$ attenuated FL-driven synaptogenesis, similar to GBP treatment, the effects on network hyperexcitability were intermediate to those seen with GBP treatment. Furthermore, GBP treatment had no effect on the residual epileptiform activity in the $\alpha 2 \delta-1 \mathrm{KO}$ animals, despite decreasing anatomic synapses. This suggests that constraining excitatory synaptogenesis is not sufficient to completely prevent hyperexcitability in the $\alpha 2 \delta-1 \mathrm{KO}$ cortex, and that deletion of $\alpha 2 \delta-1$ may cause compensatory changes that predispose the cortex to injury-induced network pathology. Genetic deletion of $\alpha 2 \delta-1$ did not alter 
the amplitude or kinetics of excitatory currents, which argues against changes in postsynaptic receptors. Therefore, presynaptic changes, via altered voltage-gated calcium channel function, or changes in neuroinflammatory response may promote hyperexcitability in the $\alpha 2 \delta-1 \mathrm{KO}$ cortex. Additionally, $\alpha 2 \delta-1 \mathrm{KO}$ may cause differences brain size, vascularization, neuronal morphology, and more, which may be relevant to FL-induced pathology.

To examine the robustness of our findings, we employed a linear mixed effect model, a statistical approach used in clinical studies. This approach revealed the effects of FL were extremely robust and the effects of GBP treatment and $\alpha 2 \delta-1 \mathrm{KO}$ in FL animals varied by assay, but were largely robust as well. Minor discrepancies between a standard statistical approach and the linear mixed effect model include the effects of GBP treatment and $\alpha 2 \delta-1 \mathrm{KO}$ on the expression of layer specific markers and of $\alpha 2 \delta-1 \mathrm{KO}$ on network hyperexcitability following FL. This approach illustrated areas that require more study before translational application; overall, however, the model confirmed that $\alpha 2 \delta-1$ signaling plays a critical role in much of the pathogenesis of the FL model.

Overall, our results show that significant $\alpha 2 \delta$-1-mediated pathologies occur in the FL model and a growing number of studies suggest that $\alpha 2 \delta$-1 signaling may contribute to the development of epilepsy. Overexpression of $\alpha 2 \delta$ - 1 in control animals leads to epileptiform EEG discharges and behavioral arrests, which are rescued by acute treatment with an anticonvulsant (Faria et al., 2017). The $\alpha 2 \delta$ - 1 ligand TSP-1 shows increased genetic variation in patients with idiopathic/genetic generalized epilepsies. Interestingly, TSP-1 mRNA levels are reduced in the ventrobasal thalamus of WAG/RiJ rats, a genetic model absence epilepsy (Santolini et al., 2017). Additionally, human mutations in $\alpha 2 \delta$-1 have been linked to polymicrogyria (Vergult et al., 2015). Whether cell death plays a role in these cases is unknown. Furthermore, the functional consequences of these mutations are not known, but gain of function mutations could increase calcium currents, increase cell death, and drive pathologic excitatory synaptogenesis. Also, although attenuating $\alpha 2 \delta$ - 1 signaling may reduce cell death and network hyperexcitability, it may compromise functional recovery. Reestablishing synaptic connectivity after injury is a critical aspect of rehabilitation and attenuating TSP1/2 signaling after stroke reduces behavioral recovery (Liauw et al., 2008). Care must be taken, therefore, in manipulating TSP $/ \alpha 2 \delta$-1 signaling, as it plays a role in both the adaptive and pathologic response to insult. Given these caveats, parsing apart the relationship between cell death, synaptogenesis, and epileptiform activity will enable us to optimize treatment strategies that target $\alpha 2 \delta$-1 signaling in neonatal injury and DCMs.

\section{References}

Andresen L, Hampton D, Taylor-Weiner A, Morel L, Yang Y, Maguire J, Dulla CG (2014) Gabapentin attenuates hyperexcitability in the freeze-lesion model of developmental cortical malformation. Neurobiol Dis 71:305-316. CrossRef Medline

Arlotta P, Molyneaux BJ, Chen J, Inoue J, Kominami R, Macklis JD (2005) Neuronal subtype-specific genes that control corticospinal motor neuron development in vivo. Neuron 45:207-221. CrossRef Medline

Armbruster M, Hampton D, Yang Y, Dulla CG (2014) Laser-scanning astrocyte mapping reveals increased glutamate-responsive domain size and disrupted maturation of glutamate uptake following neonatal cortical freeze-lesion. Front Cell Neurosci 8:277. CrossRef Medline

Barkovich AJ, Guerrini R, Kuzniecky RI, Jackson GD, Dobyns WB (2012) A developmental and genetic classification for malformations of cortical development: update 2012. Brain 135:1348-1369. CrossRef

Blümcke I, Thom M, Aronica E, Armstrong DD, Vinters HV, Palmini A, Jacques TS, Avanzini G, Barkovich AJ, Battaglia G, Becker A, Cepeda C, Cendes F, Colombo N, Crino P, Cross JH, Delalande O, Dubeau F, Duncan J, Guerrini R, et al. (2011) The clinicopathologic spectrum of focal cortical dysplasias: a consensus classification proposed by an ad hoc Task Force of the ILAE Diagnostic Methods Commission. Epilepsia 52:158-174. CrossRef

Bordey A, Lyons SA, Hablitz JJ, Sontheimer H (2001) Electrophysiological characteristics of reactive astrocytes in experimental cortical dysplasia. J Neurophysiol 85:1719-1731. Medline

Boroujerdi A, Kim HK, Lyu YS, Kim DS, Figueroa KW, Chung JM, Luo ZD (2008) Injury discharges regulate calcium channel alpha-2delta-1 subunit upregulation in the dorsal horn that contributes to initiation of neuropathic pain. Pain 139:358-366. CrossRef Medline

Campbell SL, Hablitz JJ (2008) Decreased glutamate transport enhances excitability in a rat model of cortical dysplasia. Neurobiol Dis 32:254-261. CrossRef

Campbell SL, Hablitz JJ, Olsen ML (2014) Functional changes in glutamate transporters and astrocyte biophysical properties in a rodent model of focal cortical dysplasia. Front Cell Neurosci 8:425. CrossRef

Christopherson KS, Ullian EM, Stokes CC, Mullowney CE, Hell JW, Agah A, Lawler J, Mosher DF, Bornstein P, Barres BA (2005) Thrombospondins are astrocyte-secreted proteins that promote CNS synaptogenesis. Cell 120:421-433. CrossRef Medline

Cole RL, Lechner SM, Williams ME, Prodanovich P, Bleicher L, Varney MA, Gu G (2005) Differential distribution of voltage-gated calcium channel alpha-2 delta (alpha2delta) subunit mRNAcontaining cells in the rat central nervous system and the dorsal root ganglia. J Comp Neur 491:246-269. CrossRef Medline

Crino PB (2005) Molecular pathogenesis of focal cortical dysplasia and hemimegalencephaly. J Child Neurol 20:330-336. CrossRef Medline

Dulla CG, Tani H, Brill J, Reimer RJ, Huguenard JR (2013) Glutamate biosensor imaging reveals dysregulation of glutamatergic pathways in a model of developmental cortical malformation. Neurobiol Dis 49:232-246. CrossRef

Dvorák K, Feit J (1977) Migration of neuroblasts through partial necrosis of the cerebral cortex in newborn rats-contribution to the problems of morphological development and developmental period of cerebral microgyria. Histological and autoradiographical study. Acta Neuropathol 38:203-212. Medline

Emmez H, Börcek AÖ, Kaymaz M, Kaymaz F, Durdağ E, Civi S, Gülbahar O, Aykol S, Paşaoğlu A (2010) Neuroprotective effects of gabapentin in experimental spinal cord injury. World Neurosurg 73:729-734. CrossRef Medline

Eroglu C, Allen NJ, Susman MW, O'Rourke NA, Park CY, Ozkan E, Chakraborty C, Mulinyawe SB, Annis DS, Huberman AD, Green EM, Lawler J, Dolmetsch R, Garcia KC, Smith SJ, Luo ZD, Rosenthal A, Mosher DF, Barres BA (2009) Gabapentin receptor alpha2delta-1 is a neuronal thrombospondin receptor responsible for excitatory CNS synaptogenesis. Cell 139:380-392. CrossRef Medline

Faria LC, Gu F, Parada I, Barres B, Luo ZD, Prince DA (2017) Epileptiform activity and behavioral arrests in mice overexpressing the calcium channel subunit $\alpha 2 \delta-1$. Neurobiol Dis 102:70-80. CrossRef Medline 
Fremeau RT Jr, Kam K, Qureshi T, Johnson J, Copenhagen DR, Storm MJ, Chaudhry FA, Nicoll RA, Edwards RH (2004) Vesicular glutamate transporters 1 and 2 target to functionally distinct synaptic release sites. Science 304:1815-1819. CrossRef

Fuller-Bicer GA, Varadi G, Koch SE, Ishii M, Bodi I, Kadeer N, Muth JN, Mikala G, Petrashevskaya NN, Jordan MA, Zhang SP, Qin N, Flores CM, Isaacsohn I, Varadi M, Mori Y, Jones WK, Schwartz A (2009) Targeted disruption of the voltage-dependent calcium channel alpha2/delta-1-subunit. Am J Physiol Heart Circ Physiol 297:H117-H124. CrossRef Medline

Gee NS, Brown JP, Dissanayake VU, Offord J, Thurlow R, Woodruff GN (1996) The novel anticonvulsant drug, gabapentin (Neurontin), binds to the alpha2delta subunit of a calcium channel. J Biol Chem 271:5768-5776. Medline

Hanson E, Danbolt NC, Dulla CG (2016) Astrocyte membrane properties are altered in a rat model of developmental cortical malformation but single-cell astrocytic glutamate uptake is robust. Neurobiol Dis 89:157-168. CrossRef

Hendrich J, Van Minh AT, Heblich F, Nieto-Rostro M, Watschinger K, Striessnig J, Wratten J, Davies A, Dolphin AC (2008) Pharmacological disruption of calcium channel trafficking by the alpha2delta ligand gabapentin. Proc Natl Acad Sci USA 105:3628-3633. CrossRef Medline

Hoppa MB, Lana B, Margas W, Dolphin AC, Ryan TA (2012) $\alpha 2 \delta$ expression sets presynaptic calcium channel abundance and release probability. Nature 486:122-125. CrossRef Medline

Insolera R, Bazzi H, Shao W, Anderson KV, Shi SH (2014) Cortical neurogenesis in the absence of centrioles. Nat Neurosci 17:15281535. CrossRef Medline

Ippolito DM, Eroglu C (2010) Quantifying synapses: an immunocytochemistry-based assay to quantify synapse number. J Vis Exp (45).

Jacobs KM, Gutnick MJ, Prince DA (1996) Hyperexcitability in a model of cortical maldevelopment. Cereb Cortex 6:514-523. Medline

Jacobs KM, Kharazia VN, Prince DA (1999) Mechanisms underlying epileptogenesis in cortical malformations. Epilepsy Res 36:165188. Medline

Kale A, Börcek AÖ, Emmez H, Yildirim Z, Durdağ E, Lortlar N, Kurt G, Doğulu F, Kılıç N (2011) Neuroprotective effects of gabapentin on spinal cord ischemia-reperfusion injury in rabbits. J Neurosurg Spine 15:228-237. CrossRef Medline

Kim YK, Leem JG, Sim JY, Jeong SM, Joung KW (2010) The effects of gabapentin pretreatment on brain injury induced by focal cerebral ischemia/reperfusion in the rat. Korean J Anesthesiol 58:184190. CrossRef Medline

Kim YS, Chang HK, Lee JW, Sung YH, Kim SE, Shin MS, Yi JW, Park $\mathrm{JH}$, Kim H, Kim CJ (2009) Protective effect of gabapentin on $\mathrm{N}$-methyl-D-aspartate-induced excitotoxicity in rat hippocampal CA1 neurons. J Pharmacol Sci 109:144-147. Medline

Kurshan PT, Oztan A, Schwarz TL (2009) Presynaptic alpha2delta-3 is required for synaptic morphogenesis independent of its $\mathrm{Ca} 2+-$ channel functions. Nat Neurosci 12:1415-1423. CrossRef Medline

Laird NM, Ware JH (1982) Random-effects models for longitudinal data. Biometrics 38:963-974. Medline

Leventer RJ, Guerrini R, Dobyns WB (2008) Malformations of cortical development and epilepsy. Dialogues Clin Neurosci 10:47-62. Medline

Li H, Graber KD, Jin S, McDonald W, Barres BA, Prince DA (2012) Gabapentin decreases epileptiform discharges in a chronic model of neocortical trauma. Neurobiol Dis 48:429-438. CrossRef

Li KW, Yu YP, Zhou C, Kim DS, Lin B, Sharp K, Steward O, Luo ZD (2014) Calcium channel $\alpha 2 \delta 1$ proteins mediate trigeminal neuropathic pain states associated with aberrant excitatory synaptogenesis. J Biol Chem 289:7025-7037. CrossRef Medline

Li N, Zhao CT, Wang Y, Yuan XB (2010) The transcription factor Cux1 regulates dendritic morphology of cortical pyramidal neurons. PLoS One 5:e10596. CrossRef Medline

Liauw J, Hoang S, Choi M, Eroglu C, Choi M, Sun GH, Percy M, Wildman-Tobriner B, Bliss T, Guzman RG, Barres BA, Steinberg
GK (2008) Thrombospondins 1 and 2 are necessary for synaptic plasticity and functional recovery after stroke. J Cereb Blood Flow Metab 28:1722-1732. CrossRef

Lin TN, Kim GM, Chen JJ, Cheung WM, He YY, Hsu CY (2003) Differential regulation of thrombospondin-1 and thrombospondin-2 after focal cerebral ischemia/reperfusion. Stroke 34:177-186. Medline

Luhmann HJ (2016) Models of cortical malformation-chemical and physical. J Neurosci Methods 260:62-72.

Luhmann HJ, Mittmann T, Schmidt-Kastner R, Eysel UT, MudrickDonnon LA, Heinemann U (1996) Hyperexcitability after focal lesions and transient ischemia in rat neocortex. Epilepsy Res Suppl 12:119-128. Medline

Maneuf YP, McKnight AT (2001) Block by gabapentin of the facilitation of glutamate release from rat trigeminal nucleus following activation of protein kinase $\mathrm{C}$ or adenylyl cyclase. $\mathrm{Br} \mathrm{J}$ Pharmacol 134:237-240. CrossRef Medline

Mastrolia V, Flucher SM, Obermair GJ, Drach M, Hofer H, Renström E, Schwartz A, Striessnig J, Flucher BE, Tuluc P (2017) Loss of $\alpha 2 \delta$-1 calcium channel subunit function increases the susceptibility for diabetes. Diabetes 66:897-907. CrossRef Medline

Molyneaux BJ, Arlotta P, Menezes JR, Macklis JD (2007) Neuronal subtype specification in the cerebral cortex. Nat Rev Neurosci 8:427-437. CrossRef Medline

Nieto-Rostro M, Sandhu G, Bauer CS, Jiruska P, Jefferys JG, Dolphin AC (2014) Altered expression of the voltage-gated calcium channel subunit $\alpha_{2} \delta-1$ : a comparison between two experimental models of epilepsy and a sensory nerve ligation model of neuropathic pain. Neuroscience 283:124-137. CrossRef

Ning M, Sarracino DA, Kho AT, Guo S, Lee SR, Krastins B, Buonanno FS, Vizcaíno JA, Orchard S, McMullin D, Wang X, Lo EH (2011) Proteomic temporal profile of human brain endothelium after oxidative stress. Stroke 42:37-43. CrossRef Medline

Patel R, Bauer CS, Nieto-Rostro M, Margas W, Ferron L, Chaggar K, Crews K, Ramirez JD, Bennett DL, Schwartz A, Dickenson AH, Dolphin AC (2013) $\alpha 2 \delta$-1 gene deletion affects somatosensory neuron function and delays mechanical hypersensitivity in response to peripheral nerve damage. J Neurosci 33:16412-16426. CrossRef

Sansregret L, Nepveu A (2008) The multiple roles of CUX1: insights from mouse models and cell-based assays. Gene 412:84-94. CrossRef Medline

Santolini I, Celli R, Cannella M, Imbriglio T, Guiducci M, Parisi P, Schubert J, lacomino M, Zara F, Lerche H; EuroEPINOMICS CoGIE Consortium; Genetic Commission of Italian League Against Epilepsy (LICE), Moyanova S, Ngomba RT, van Luijtelaar G, Battaglia G, Bruno V, Striano P, Nicoletti F (2017) Alterations in the $\alpha 2 \delta$ ligand, thrombospondin-1, in a rat model of spontaneous absence epilepsy and in patients with idiopathic/genetic generalized epilepsies. Epilepsia 58:1993-2001. CrossRef Medline

Sun QQ, Zhou C, Yang W, Petrus D (2016) Continuous spike-waves during slow-wave sleep in a mouse model of focal cortical dysplasia. Epilepsia 57:1581-1593. CrossRef

Takahashi DK, Jin S, Prince DA (2017) Gabapentin prevents progressive increases in excitatory connectivity and epileptogenesis following neocortical trauma. Cereb Cortex 1-16.

Takano T, Sokoda T, Akahori S, Sakaue Y, Sawai C, Takeuchi Y, Ohno M (2006) Enhanced capacity of epilepsy in brain malformation produced during early development. Pediatr Neurol 35:38-41. CrossRef Medline

Traa BS, Mulholland JD, Kadam SD, Johnston MV, Comi AM (2008) Gabapentin neuroprotection and seizure suppression in immature mouse brain ischemia. Pediatr Res 64:81-85. CrossRef Medline

Vergult S, Dheedene A, Meurs A, Faes F, Isidor B, Janssens S, Gautier A, Le Caignec C, Menten B (2015) Genomic aberrations of the CACNA2D1 gene in three patients with epilepsy and intellectual disability. Eur J Hum Genet 23:628-632. CrossRef Medline

Wang JL, Jin GL, Yuan ZG, Yu XB, Li JQ, Qiu TL, Dai RX (2016) Plasma thrombospondin-1 and clinical outcomes in traumatic brain injury. Acta Neurol Scand 134:189-196. CrossRef Medline 
Watanabe M, Hitomi M, van der Wee K, Rothenberg F, Fisher SA, Zucker R, Svoboda KK, Goldsmith EC, Heiskanen KM, Nieminen AL (2002) The pros and cons of apoptosis assays for use in the study of cells, tissues, and organs. Microsc Microanal 8:375-391. CrossRef

Williams AJ, Bautista CC, Chen RW, Dave JR, Lu XC, Tortella FC, Hartings JA (2006) Evaluation of gabapentin and ethosuximide for treatment of acute nonconvulsive seizures following ischemic brain injury in rats. J Pharmacol Exp Ther 318:947-955. CrossRef Medline

Williams AJ, Zhou C, Sun QQ (2016) Enhanced burst-suppression and disruption of local field potential synchrony in a mouse model of focal cortical dysplasia exhibiting spike-wave seizures. Front Neural Circuits 10:93. CrossRef
Yang RH, Wang WT, Chen JY, Xie RG, Hu SJ (2009) Gabapentin selectively reduces persistent sodium current in injured type-A dorsal root ganglion neurons. Pain 143:48-55. CrossRef Medline Yeh CY, Chung SC, Tseng FL, Tsai YC, Liu YC (2011) Biphasic effects of chronic intrathecal gabapentin administration on the expression of protein kinase $\mathrm{C}$ gamma in the spinal cord of neuropathic pain rats. Acta Anaesthesiol Taiwan 49:144-148. CrossRef

Zhang Y, Chen K, Sloan SA, Bennett ML, Scholze AR, O'Keeffe S, Phatnani HP, Guarnieri P, Caneda C, Ruderisch N, Deng S, Liddelow SA, Zhang C, Daneman R, Maniatis T, Barres BA, Wu JQ (2014) An RNA-sequencing transcriptome and splicing database of glia, neurons, and vascular cells of the cerebral cortex. J Neurosci 34:11929-11947. CrossRef 